\title{
Monitoring Exhaled Carbon Dioxide
}

\author{
Mark S Siobal RRT-ACCS FAARC
}

\author{
Introduction \\ Classification and Types of Exhaled $\mathrm{CO}_{2}$ Monitoring \\ Colorimetric $\mathrm{CO}_{2}$ Detectors \\ Mainstream $\mathrm{CO}_{2}$ Monitoring \\ Sidestream $\mathrm{CO}_{2}$ Monitoring \\ Capnometry Versus Capnography \\ Indications for Exhaled $\mathrm{CO}_{2}$ Monitoring \\ Monitoring Adequacy of Ventilation \\ Confirmation of Endotracheal Intubation \\ Monitoring Respiratory Status \\ Monitoring During Cardiopulmonary Resuscitation \\ Volumetric Capnography \\ Phases of the Volumetric Capnogram \\ Fowler Dead Space \\ Single-Breath $\mathrm{CO}_{2}$ Analysis \\ Measuring Physiologic Dead Space \\ Clinical Usefulness of Physiologic Dead Space Measurements \\ Assessing the Severity of Lung Injury \\ Predicting Survival in ARDS Patients \\ Indication of Lung Recruitment Versus Overdistension \\ Predicting Successful Liberation from Mechanical Ventilation \\ Diagnosis of Pulmonary Embolism \\ Bohr Versus Enghoff Approach to Physiologic Dead Space Measurements \\ Estimating Metabolic Rate and Resting Energy Expenditure \\ Summary
}

In the past few decades, assessment of exhaled $\mathrm{CO}_{2}$ in both intubated and non-intubated patients has evolved into an essential component in many aspects of patient monitoring. Besides the basic assessment of ventilation, exhaled $\mathrm{CO}_{2}$ monitoring can provide valuable patient safety information and critical physiologic data in regard to the ventilation and perfusion matching in the lungs, cardiac output, and metabolic rate. Despite these important clinical monitoring benefits and widespread availability, exhaled $\mathrm{CO}_{2}$ monitoring is often underutilized. The purpose of this paper is to review the importance and present the extensive body of knowledge to support the use of exhaled $\mathrm{CO}_{2}$ monitoring in various areas of clinical practice. Advanced application concepts and the future development of exhaled $\mathrm{CO}_{2}$ monitoring will also be discussed. Key words: end-tidal $\mathrm{CO}_{2}$; capnometry; capnography; capnogram; volumetric capnography; physiologic dead space; resting energy expenditure. [Respir Care 2016;61(10):1397-1416. (C) 2016 Daedalus Enterprises] 


\section{Monitoring Exhaled Carbon Dioxide}

\section{Introduction}

The measurement of $\mathrm{CO}_{2}$ in air was first developed around 1918 and performed to analyze gas concentrations in mines. ${ }^{1}$ This process of analysis was painstakingly tedious, using an intricate apparatus that involved measuring quantities of $\mathrm{CO}_{2}$ and other gases that were chemically absorbed from a known gas volume. The volume of absorbed $\mathrm{CO}_{2}$ was then compared with the total gas volume, which yielded the fraction or percentage of $\mathrm{CO}_{2}$ present. A decade later, a technique was developed to analyze exhaled $\mathrm{CO}_{2}$ from a single breath during vigorous exercise. ${ }^{2}$ This process entailed capturing exhaled gas using a system the size of a telephone booth consisting of a series of electro-mechanically controlled valves, which directed sequential portions of expired air into 6 small rubber bags. The collected $\mathrm{CO}_{2}$ in each bag was then analyzed multiple times to yield the average $\mathrm{CO}_{2}$, which was plotted over time, thus resulting in the first exhaled capnogram. By the 1970s, exhaled $\mathrm{CO}_{2}$ was monitored in ICUs using mass spectrometry systems that aspirated exhaled gas through long lengths of capillary tubing to a central monitoring location. ${ }^{3,4}$ Periodic measurements of the partial pressure of end-tidal $\mathrm{CO}_{2}\left(\mathrm{P}_{\mathrm{ETCO}_{2}}\right)$ occurred on a timed schedule or in a sequential loop as the sampling cycle rotated between a number of monitored beds. ${ }^{4}$ With the introduction of the smaller infrared sensor, portable exhaled $\mathrm{CO}_{2}$ monitors came to the bedside in the $1980 \mathrm{~s} .{ }^{5}$ Miniature $\mathrm{CO}_{2}$ monitors that can fit into the palm of the hand and are capable of displaying an exhaled $\mathrm{CO}_{2}$ capnogram are currently available. ${ }^{6,7}$

The technological advancement of exhaled $\mathrm{CO}_{2}$ monitoring has coincided with the progression of use and importance in clinical practice. The significance of exhaled $\mathrm{CO}_{2}$ monitoring extends well beyond the very basic utilization of monitoring the adequacy of ventilation. Detection of exhaled $\mathrm{CO}_{2}$ has proven to be an invaluable mechanism for confirming tracheal intubation, recognizing accidental esophageal intubations, and other critical patient safety benefits. The patient protection enhancements provided by $\mathrm{CO}_{2}$ monitoring also include: the detection of invasive airway disconnection, dislodgement, or obstruc-

\footnotetext{
Mr Siobal is affiliated with the BSRC Program, Skyline College, San Bruno, California. Mr Siobal has disclosed relationships with Aerogen, Sunovion, and Mallinckrodt.

Correspondence: Mark S Siobal RRT-ACCS FAARC. E-mail: siobalm@smccd.edu.

Mr Siobal presented a version of this paper at the 31st Annual New Horizons Symposium: Monitoring of the AARC Congress 2015, held November 7-10, 2015 in Tampa, Florida.
}

DOI: $10.4187 /$ respcare.04919 tion and monitoring for respiratory depression postoperatively, during procedural sedation, and during patientcontrolled analgesia. Of critical significance is the use of $\mathrm{P}_{\mathrm{ETCO}_{2}}$ to gauge the effectiveness of cardiopulmonary resuscitation (CPR), to predict outcome, and to guide the continuation of resuscitation efforts. ${ }^{8}$ Exhaled $\mathrm{CO}_{2}$ can also be described as the vital sign for ventilation and perfusion because the volume of $\mathrm{CO}_{2}$ excreted by the cardiorespiratory system is a sensitive indicator not only of ventilation efficiency but also of pulmonary perfusion and cardiac output. The volume of exhaled $\mathrm{CO}_{2}$ per minute $\left(\dot{\mathrm{V}}_{\mathrm{CO}_{2}}\right)$ can also be used to estimate the metabolic rate and nutritional requirements of the critically ill patient. ${ }^{9}$

The recognition and importance of monitoring exhaled $\mathrm{CO}_{2}$ in many areas of patient care has led to the expanding recommendation for its use by regulatory agencies and inclusion in the standards and practice guidelines of many professional organizations, such as the American Society for Anesthesia (ASA), the American Heart Association, the American Association for Respiratory Care, the Joint Commission, and the Centers for Medicare and Medicaid Services. Despite this heightened level of awareness and the regulatory and organizational guidance, exhaled $\mathrm{CO}_{2}$ monitoring is often underutilized. ${ }^{8,10-16}$

The reasons for this disparity between knowledge and practice may be due in part to the cost burden of acquiring the technology; the clinician time required for set-up, maintenance, and troubleshooting; and the lack of awareness of best practices for optimal utilization. Universally accepted standards of care mandating the use of $\mathrm{CO}_{2}$ monitoring in specific circumstances or patient categories yielding the highest potential to impact patient safety and influence outcomes are also lacking.

The purpose of this review is to increase the awareness and understanding of health-care providers of the importance of exhaled $\mathrm{CO}_{2}$ monitoring and its application in clinical practice. An appraisal of the different technologies will be followed by a review of the recognized indications for monitoring and an assessment of the potential for further advancements in exhaled $\mathrm{CO}_{2}$ monitoring.

\section{Classification and Types of Exhaled $\mathrm{CO}_{2}$ Monitoring}

Understanding available technologies and how they functions can provide important insights into their appropriate application, potential limitations, and problems associated with use. The following is a brief review of the classification and types of exhaled $\mathrm{CO}_{2}$ monitoring commonly utilized.

\section{Colorimetric $\mathrm{CO}_{2}$ Detectors}

Colorimetric $\mathrm{CO}_{2}$ detectors provide continuous qualitative and semi-quantitative exhaled $\mathrm{CO}_{2}$ monitoring. Col- 
orimetric $\mathrm{CO}_{2}$ detectors are the simplest form of $\mathrm{CO}_{2}$ monitors. They are portable, disposable, inexpensive, single-use devices that can rapidly detect and confirm tracheal intubation and estimate the amount of $\mathrm{CO}_{2}$ in exhaled gas. Colorimetric detectors contain chemically treated material that is $\mathrm{pH}$-sensitive and colorimetrically reflects $\mathrm{CO}_{2}$ concentrations in expired gas. ${ }^{17}$ Limitations of colorimetric $\mathrm{CO}_{2}$ detectors include false positive readings when the detection medium is contaminated with gastric acid or acidic solutions instilled through an endotracheal tube. ${ }^{17,18}$

\section{Mainstream $\mathrm{CO}_{2}$ Monitoring}

Mainstream $\mathrm{CO}_{2}$ monitoring devices utilize a small infrared sensor consisting of a sample cell or cuvette and an infrared optical bench placed within the gas flow pathway at the airway. This measurement location results in realtime $\mathrm{CO}_{2}$ values within the airway and a real-time graphical representation of the $\mathrm{CO}_{2}$ waveform plotted over time or by the exhaled volume. Disadvantages of mainstream $\mathrm{CO}_{2}$ monitoring include: cost of the sensor; potential for damage to the sensor and connecting cable during handling and patient monitoring; increased circuit mechanical dead space; potential for fouling with coughed up secretions and circuit condensate; and the additional weight of the sensor, airway adapter, and cable at the patient's airway connection. Also, many mainstream devices are limited to use with intubated patients only. ${ }^{19}$

\section{Sidestream $\mathrm{CO}_{2}$ Monitoring}

Sidestream $\mathrm{CO}_{2}$ monitoring devices aspirate a gas sample from a ventilator breathing circuit or other patient interface device through a length of small-bore tubing. Different interface designs for use on non-intubated patients incorporate nasal and oral sampling points to improve measurement accuracy. Several interface designs include the ability to simultaneously administer oxygen through a split channel device. Sidestream sampling devices utilize an infrared $\mathrm{CO}_{2}$ sensor in a monitor located away from the patient and can only be displayed in a time-based waveform. Time-based sidestream $\mathrm{CO}_{2}$ monitoring is the type more commonly used in the operating room setting, during non-intubated patient monitoring, and during CPR.

The sidestream sample method often requires use of a water trap and or specialized tubing that removes water vapor before analysis to prevent blockage and contamination of the sample tubing. Sample analysis located away from the patient results in a time delay often several seconds in duration before measured results are displayed. Since sidestream sampling requires a continuous aspirated sample flow rate from the ventilator circuit, interference with the measurement of ventilation parameters and the

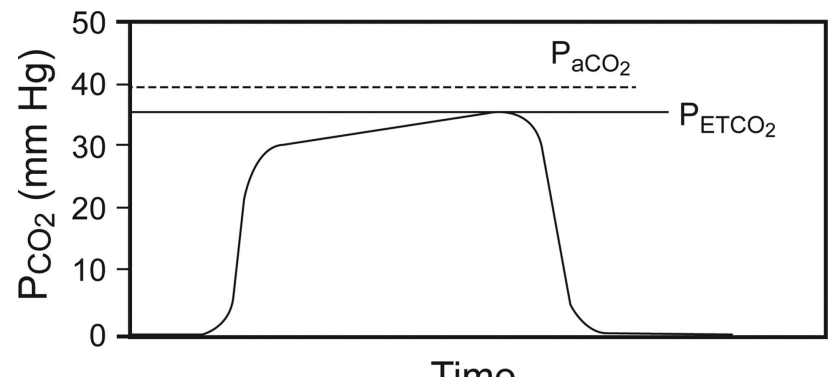

Time

Fig. 1. Normal time-based capnogram showing the difference between the $\mathrm{P}_{\mathrm{aCO}}$ and partial pressure of end tidal $\mathrm{CO}_{2}\left(\mathrm{P}_{\mathrm{ETCO}}\right)$, which is normally $2-5 \mathrm{~mm} \mathrm{Hg}$.

triggering mechanism can occur. Also, when sidestream systems are used intra-operatively with inhaled anesthetic agents, a scavenging system is required to prevent ambient contamination and health-care provider exposures. ${ }^{19}$

\section{Capnometry Versus Capnography}

Capnometry is performed by a capnometer. A capnometer is a monitor that measures $\mathrm{CO}_{2}$ concentrations in respired gases over time and displays numeric values for $\mathrm{P}_{\mathrm{ETCO}_{2}}$, respiratory frequency, and sometimes the inspired $\mathrm{CO}_{2}$ concentration or partial pressure. Capnometers can be either mainstream or sidestream in design..$^{20,21}$

The terms capnometry and capnography are often used synonymously, but in contrast to capnometry, capnography is performed by a capnograph, a monitor that is functionally the same as a capnometer but incorporates the additional feature of displaying the $\mathrm{CO}_{2}$ waveform known as a capnogram (Fig. 1). Capnographs can also be mainstream or sidestream in design. The additional clinical monitoring value of capnography is the ability to visually interpret the waveform and morphology of the capnogram. The value of viewing the capnogram is synonymous with the revelation of knowing the heart rate and seeing the electrocardiogram. Interpretation of the different phases; the shape, area, and slope of the capnogram segments; and integration of the exhaled capnogram to exhaled tidal volume reveal clinically valuable information regarding ventilation and perfusion and cardiopulmonary physiology..$^{20,21}$

\section{Indications for Exhaled $\mathrm{CO}_{2}$ Monitoring}

Exhaled $\mathrm{CO}_{2}$ monitoring is essential and useful in clinical practice for an array of monitoring indications, including ventilation, circulation, metabolism, improving patient safety, and influencing and predicting outcomes of care. Following is a review of the indications for exhaled $\mathrm{CO}_{2}$ monitoring for in- and out-of-hospital monitoring of intubated and non-intubated adult and pediatric patients. 


\section{Monitoring Exhaled Carbon Dioxide}

\section{Monitoring Adequacy of Ventilation}

Continuous monitoring of exhaled $\mathrm{CO}_{2}$ from the onset of intubation to extubation, whether by capnometry or capnography, is an accepted method to ensure adequate ventilation during mechanical ventilation in both adult and pediatric patients. ${ }^{14,22} \mathrm{CO}_{2}$ monitoring in non-intubated adult, ${ }^{13,23,24}$ neonatal, and pediatric patients ${ }^{25-27}$ can also be effective. As a reflection of this potential benefit, the ASA has identified $\mathrm{CO}_{2}$ monitoring as a standard of care in anesthesia monitoring since $1986 .{ }^{28}$ In healthy patients during mechanical ventilation, $\mathrm{P}_{\mathrm{ETCO}_{2}}$ closely approximates $\mathrm{P}_{\mathrm{aCO}_{2}}$ and is usually 2-5 mm Hg lower ${ }^{29-31}$ and therefore can be an effective index of the adequacy of ventilation (see Fig. 1).

However, it should be well understood by all clinicians that in diseased states, such as ARDS, COPD, and asthma, ventilation/perfusion ( $\dot{\mathrm{V} / \mathrm{Q}})$ mismatch in the lungs can cause the $\mathrm{P}_{\mathrm{aCO}}-\mathrm{P}_{\mathrm{ETCO}_{2}}$ difference to increase. An increased $\mathrm{P}_{\mathrm{aCO}_{2}}-\mathrm{P}_{\mathrm{ETCO}_{2}}$ difference can occur to varying degrees with increased physiologic dead space, shunt perfusion, low cardiac output, and conditions of low $\dot{\mathrm{V} / \mathrm{Q} \text {. }}$

It has been suggested that the lack of agreement with $\mathrm{P}_{\mathrm{aCO}_{2}}$ in diseased lungs has negatively impacted the perception of value and the use of $\mathrm{CO}_{2}$ monitoring. ${ }^{8}$ Contrary to this misinterpretation, when a large $\mathrm{P}_{\mathrm{aCO}}-\mathrm{P}_{\mathrm{ETCO}_{2}}$ difference exists, $\mathrm{P}_{\mathrm{ETCO}_{2}}$ can be an effective means of trending changes in $\mathrm{P}_{\mathrm{aCO}}$ and the efficiency of ventilation and changes in the physiologic dead space fraction $\left(\mathrm{V}_{\mathrm{D}} / \mathrm{V}_{\mathrm{T}}\right){ }^{32} \mathrm{It}$ is therefore important to recognize that the $\mathrm{P}_{\mathrm{aCO}_{2}}-\mathrm{P}_{\mathrm{ETCO}_{2}}$ difference can be an indication of the degree of lung injury and correlates with increased $\mathrm{V}_{\mathrm{D}} / \mathrm{V}_{\mathrm{T}} \cdot 5,32,33$

Furthermore, intra-operative monitoring of the $\mathrm{P}_{\mathrm{aCO}_{2}}-$ $\mathrm{P}_{\mathrm{ETCO}_{2}}$ difference has been shown to predict mortality in trauma patients. Patients with a $\mathrm{P}_{\mathrm{aCO}_{2}}-\mathrm{P}_{\mathrm{ETCO}_{2}}$ difference $>8-10 \mathrm{~mm} \mathrm{Hg}$ had higher mortality rates both intra-operatively ${ }^{34-37}$ and following emergent surgeries. ${ }^{34,37}$

Other sometimes overlooked benefits of monitoring the $\mathrm{P}_{\mathrm{aCO}_{2}}-\mathrm{P}_{\mathrm{ETCO}_{2}}$ difference to assess the adequacy of ventilation include: the reduction of arterial blood gas utilization, ${ }^{38}$ which impacts unnecessary blood loss and costs; the identification and prevention of excessive ventilation and hyperventilation in neurotrauma patients ${ }^{39-43}$; and the affect that visual interpretation of the capnogram has had on enhancing monitoring during mechanical ventilation and airway management. ${ }^{44}$

\section{Confirmation of Endotracheal Intubation}

Perhaps one of the most significant impacts of exhaled $\mathrm{CO}_{2}$ monitoring is in its use as a definitive method for confirming endotracheal intubation and the reduction in harm associated with identifying the serious consequences of accidental esophageal intubation, death and anoxic brain injury. Use of a $\mathrm{CO}_{2}$ monitor in addition to direct visualization of the endotracheal tube passing through the vocal cords represent the accepted standards in clinical practice for confirming intubation in adult, pediatric, and neonatal patients. ${ }^{45-49}$

Capnography and capnometry compared with auscultation have been shown to be the most reliable methods to confirm endotracheal tube placement in the prehospital emergency setting. ${ }^{50}$ Several studies have demonstrated that when continuous $\mathrm{P}_{\mathrm{ETCO}}$ monitoring is used, the sensitivity (true positive rate) and specificity (true negative rate) for confirming endotracheal intubation are both $100 \% .^{50-52}$ Colorimetric detectors were also found to be highly sensitive (88-98\%) and 100\% specific in confirming proper endotracheal intubation ${ }^{17,18}$ and useful in guiding and predicting successful resuscitation in non-cardiac arrest patients. ${ }^{17,18,53}$ Rates of unrecognized misplaced endotracheal tubes in out-of-hospital arrests as high as $23 \%$ have been reported when continuous $\mathrm{P}_{\mathrm{ETCO}}$ monitoring was not used. ${ }^{52}$

Recognition of these important facts by the ASA, 28,54 the American Association for Respiratory Care, ${ }^{55}$ the American Heart Association, ${ }^{56,57}$ Emergency Medical Services systems, ${ }^{42,58}$ the Intensive Care Society in the United Kingdom, ${ }^{42}$ the Royal College of Anesthetists, and the Association of Anesthetists of Great Britain and Ireland, ${ }^{16}$ has resulted in the inclusion of the use of $\mathrm{CO}_{2}$ monitoring during intubations in their respective standards of practice, clinical practice guidelines, and practice recommendations. This compelling body of evidence mandates the use of $\mathrm{CO}_{2}$ monitoring during intubation as a universal standard of care for confirming endotracheal intubation. ${ }^{11}$ Nevertheless, It should be well understood that during cardiac arrest, the accuracy for confirming proper endotracheal intubation using $\mathrm{CO}_{2}$ monitoring is diminished due the absence of cardiac output, pulmonary blood flow, and therefore exhaled $\mathrm{CO}_{2} \cdot{ }^{17,18,50}$ In this situation, the absence of exhaled $\mathrm{CO}_{2}$ using any $\mathrm{CO}_{2}$ monitoring device may be mistakenly interpreted as an esophageal intubation.

\section{Monitoring Respiratory Status}

The use of exhaled $\mathrm{CO}_{2}$ to monitor respiratory status is another area of growing significance and interest. Exhaled $\mathrm{CO}_{2}$ offers an accurate and reliable means of measuring respiratory frequency. An elevated respiratory frequency is a sensitive and reasonably specific marker of respiratory dysfunction. ${ }^{59}$ A low respiratory frequency is an indicator of respiratory depression from opioid analgesia and can be detected early by exhaled $\mathrm{CO}_{2}$ monitoring. ${ }^{60}$

Opioid-induced respiratory depression in the post-anesthesia care period is a major concern emphasized by ASAmandated standards, ${ }^{28}$ the Joint Commission Sentinel Event Alerts, ${ }^{61}$ and the Centers for Medicare and Medicaid Ser- 
Table 1. Characteristics of Bradypneic (Type 1) and Hypopneic (Type 2) Hypoventilation ${ }^{70}$

\begin{tabular}{|c|c|c|c|c|c|c|}
\hline Hypoventilation Classification & Respiratory Frequency & Tidal Volume & Anatomic Dead Space & $\mathrm{V}_{\mathrm{D}} / \mathrm{V}_{\mathrm{T}}$ & $\mathrm{P}_{\mathrm{ETCO}_{2}}$ & $\mathrm{P}_{\mathrm{aCO}_{2}}$ \\
\hline Type 1 (bradypneic) & --- & - & No change & Minimal change & + & + \\
\hline Type 2 (hypopneic) & - & --- & No change & +++ & - or no change & + \\
\hline $\begin{array}{l}\mathrm{V}_{\mathrm{D}}=\text { dead space volume } \\
\mathrm{V}_{\mathrm{T}}=\text { tidal volume } \\
\mathrm{P}_{\mathrm{ETCO}}=\text { end-tidal } \mathrm{CO}_{2} \\
-=\text { decrease } \\
+=\text { increase }\end{array}$ & & & & & & \\
\hline
\end{tabular}

vices Regulations and Interpretive Guidelines for Hospitals. ${ }^{62}$ Because oxygenation and ventilation are separate physiologic processes, pulse oximetry monitoring of oxygenation alone should not be considered a suitable monitor of ventilatory function. ${ }^{61-64}$ Oxygen saturation is frequently maintained, even at a low breathing frequency, and pulse oximetry alone often fails to detect respiratory depression, hypoventilation, and apnea episodes primarily when the patient is receiving supplemental oxygen. ${ }^{65}$ Therefore, the application of exhaled $\mathrm{CO}_{2}$ monitoring in the post-anesthesia setting, during procedural sedation, and when administering opiate analgesia can provide an important early warning of ventilatory compromise in adult and pediatric patients. ${ }^{65-69}$

A significant limitation to consider while using $\mathrm{P}_{\mathrm{ETCO}_{2}}$ monitoring to detect respiratory depression is that there are 2 different types of drug-induced hypoventilation (Table 1). Type 1 or bradypneic hypoventilation is characterized by a decreased respiratory frequency, a slightly decreased tidal volume, and an increased $\mathrm{P}_{\mathrm{ETCO}_{2}}$ and $\mathrm{P}_{\mathrm{aCO}}$. Type 2 or hypopneic hypoventilation, on the other hand, is characterized by a significant decrease in tidal volume, slightly decreased respiratory frequency, and a decreased or normal $\mathrm{P}_{\mathrm{ETCO}_{2}}$, whereas the $\mathrm{P}_{\mathrm{aCO}}$ can be elevated. ${ }^{70}$

During hypopneic hypoventilation, the shallow breathing and smaller tidal volumes in proportion to the anatomical dead space cause decreased alveolar ventilation, increased dead space ventilation, increased $\mathrm{P}_{\mathrm{aCO}_{2}}$, and an increased $\mathrm{P}_{\mathrm{aCO}}-\mathrm{P}_{\mathrm{ETCO}_{2}}$ difference. This significant distinction between bradypneic and hypopneic hypoventilation is critical for clinicians to acknowledge and comprehend. Low or normal $\mathrm{P}_{\mathrm{ETCO}_{2}}$ during hypopneic hypoventilation can be accompanied by significant respiratory depression and a markedly elevated $\mathrm{P}_{\mathrm{aCO}}$, which may go unrecognized if patient monitoring focuses on the value of $\mathrm{P}_{\mathrm{ETCO}_{2}}$.

Another area of concern is the growing evidence that the use of patient-controlled analgesia (PCA) imposes significant risks to patients and potential liability exposure to health-care providers and hospitals. This is again reflected in position statements and guidelines from the ASA, ${ }^{71,72}$ the Centers for Medicare and Medicaid Services, ${ }^{62}$ the Joint Commission, ${ }^{73}$ the Anesthesia Patient Safety Foun- dation, ${ }^{74,75}$ and the Institute for Safe Medication Practices, ${ }^{64}$ which recommend continuous $\mathrm{P}_{\mathrm{ETCO}_{2}}$ monitoring to guard against opioid-induced respiratory depression during PCA use. Of particular concern driving these recommendations are well-documented cases of "PCA by proxy" in which a family member or health-care provider, and not the patient, administers PCA doses. This has led to serious and fatal outcomes considered possibly preventable if $\mathrm{P}_{\mathrm{ETCO}_{2}}$ monitoring were being used. ${ }^{73,76-78}$

Furthermore, the value of $\mathrm{CO}_{2}$ monitoring during procedural sedation $8,26,28,71,79,80$ and in the emergency department as an early indication of respiratory depression, especially when patients are receiving oxygen, ${ }^{65,81,82}$ to aid in the identification of the severity of illness and to improve patient safety ${ }^{13,70,83-85}$ is also increasingly being mandated for adult and pediatric patients.

\section{Monitoring During CPR}

It has been well substantiated that exhaled $\mathrm{CO}_{2}$ monitoring during CPR provides invaluable information regarding the correct placement of an advanced airway, ${ }^{28,50,52,56,57,86}$ the effectiveness of cardiac compressions, $56,86-88$ the return of spontaneous circulation, ${ }^{56,86,87,89,90}$ and the prediction of outcome and survival during cardiac arrest. ${ }^{86,87,91}$

The value of exhaled $\mathrm{CO}_{2}$ monitoring as a guide to the effectiveness of cardiac compressions was first demonstrated in 1978 from a series of 3 patients during CPR. ${ }^{91}$ Subsequent animal studies demonstrated that $\mathrm{P}_{\mathrm{ETCO}_{2}}$ correlated with cardiac output and the adequacy of CPR and was useful as a guide to successful CPR and predicted the return of spontaneous circulation..$^{92-95}$ These findings were confirmed in 4 studies of human subjects, which indicated that when $\mathrm{P}_{\mathrm{ETCO}_{2}}$ was $<10 \mathrm{~mm} \mathrm{Hg}$ during CPR, patients did not survive ${ }^{96-99}$ (Fig. 2).

These data provide evidence to support a $\mathrm{P}_{\mathrm{ETCO}_{2}}$ threshold target value $>10 \mathrm{~mm} \mathrm{Hg}$ during CPR. Additional investigations also demonstrated that changes in $\mathrm{P}_{\mathrm{ETCO}}$ during resuscitation attempts predicted outcomes and return of spontaneous circulation, ${ }^{89,100}$ suggesting that $\mathrm{P}_{\mathrm{ETCO}_{2}}$ could be useful in deciding when to terminate resuscitation efforts in adult and pediatric patients. ${ }^{101}$ When the value of 


\section{Monitoring Exhaled CARbon Dioxide}

$\mathrm{P}_{\mathrm{ETCO}_{2}}$ at 20 min after the initiation of CPR was used as a screening test to predict return of spontaneous circulation, a threshold value of $14 \mathrm{~mm} \mathrm{Hg}$ or less had a sensitivity, specificity, positive predictive value (accuracy of positive results), and negative predictive value (accuracy of negative results) of $100 \% .100$

$\mathrm{P}_{\mathrm{ETCO}_{2}}$ monitoring during $\mathrm{CPR}$ can be an effective tool to detect the effectiveness of external cardiac compression and the development of rescuer fatigue. Additionally, a sudden increase in continuously monitored $\mathrm{P}_{\mathrm{ETCO}_{2}}$ during high quality CPR was associated with the return of spontaneous circulation ${ }^{89}$ (Fig. 3).

This evidence supports the use of $\mathrm{P}_{\mathrm{ETCO}_{2}}$ monitoring during CPR in both in- and out-of-hospital resuscitations. The use of quantitative waveform capnography interpretation has been incorporated into advanced cardiac life support training to confirm advance airway placement and

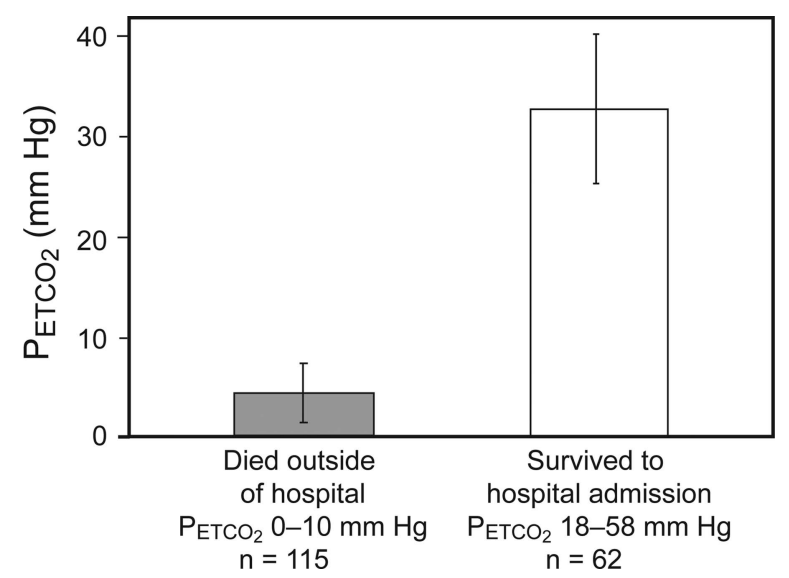

Fig. 2. Mean end tidal carbon dioxide $\left(\mathrm{P}_{\mathrm{ETCO}_{2}}\right)$ differences between survivors and non-survivors after 20 min of advanced cardiac life support during out-of-hospital cardiac arrest. Subjects with $\mathrm{P}_{\mathrm{ETCO}}$ levels of $\leq 10 \mathrm{~mm} \mathrm{Hg}$ died before reaching the hospital. Data from Reference 98. to monitor resuscitation effectiveness since $2010 .{ }^{56}$ The union between evidence for clinical practice and technology has resulted in the availability of exhaled $\mathrm{CO}_{2}$ monitoring as a feature incorporated into new state-of-the-art defibrillators and transport monitors.

\section{Volumetric Capnography}

Volumetric capnography differs from standard capnography in that exhaled $\mathrm{CO}_{2}$ is plotted against the exhaled tidal volume. Analysis of the phases of the volumetric capnogram, the shape and curve morphology, and measurements based on calculations from the volumetric capnogram can reveal important information in regard to the efficiency of ventilation and perfusion, the physiologic dead space fraction, and the metabolic rate of the patient. ${ }^{102}$

\section{Phases of the Volumetric Capnogram}

The 3 phases of the volumetric capnogram are synonymous with the phases of the time-based capnogram. Phase 1 characterizes emptying of the anatomic dead space (the conducting airways), where exhaled $\mathrm{CO}_{2}$ is near zero. Phase 2 represents a mixture of gas from the anatomic dead space and alveolar gas containing $\mathrm{CO}_{2}$. Phase 3 signifies emptying of alveolar air spaces (also known as the alveolar plateau), the end point of which is equal to the endtidal $\mathrm{CO}_{2}$ (Fig. 4). An increase in slope of the rise of phase 3 signifies an increase in the number alveolar gas exchange units with varying degrees of $\dot{V} / \mathbf{Q}$ mismatch, such as during airway obstruction and elevated alveolar dead space. ${ }^{102}$

\section{Fowler Dead Space}

Using the principles described by Fowler, 103 the anatomical dead space volume can be identified and measured
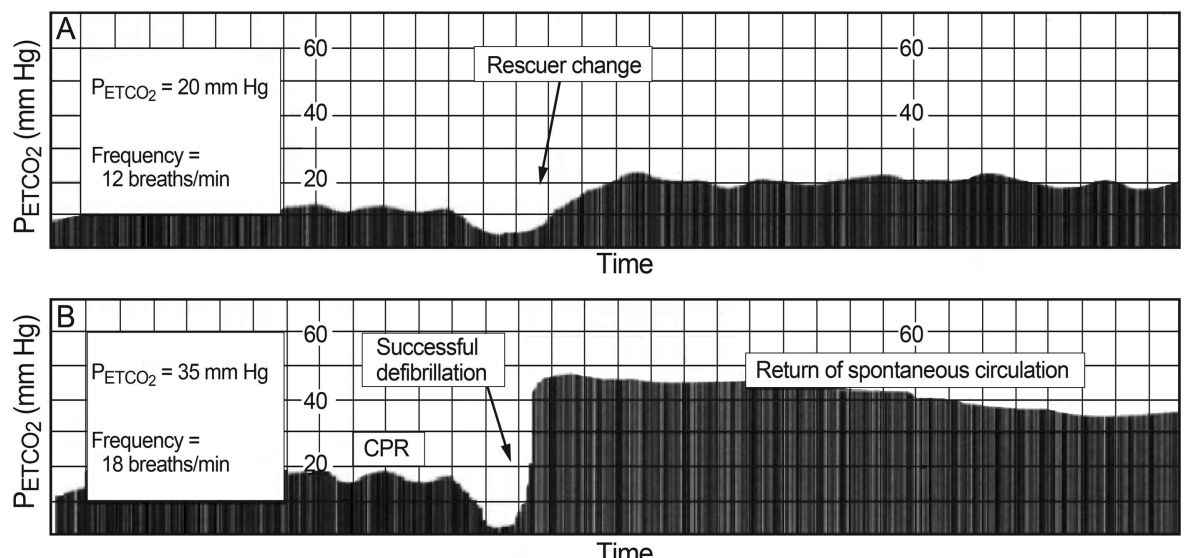

Fig. 3. Time-compressed capnograms of end-tidal carbon dioxide $\left(\mathrm{P}_{\mathrm{ETCO}_{2}}\right)$ during cardiopulmonary resuscitation (CPR), showing ineffective cardiac compressions or rescuer fatigue (A) and return of spontaneous circulation (B). Courtesy Philips Healthcare. 


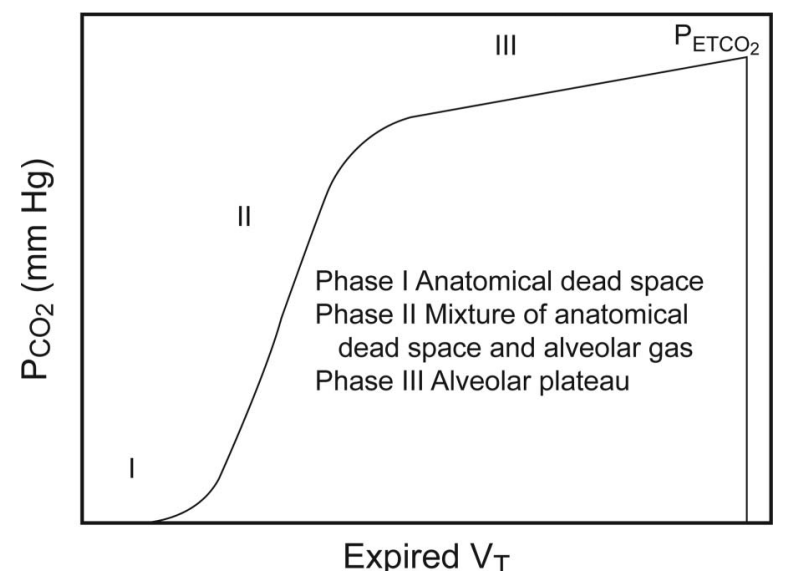

Fig. 4. The 3 phases of the exhaled $\mathrm{CO}_{2}$ volumetric capnogram indicate the different stages of airway and alveolar gas emptying and terminate at the end-tidal carbon dioxide $\left(\mathrm{P}_{\mathrm{ETCO}_{2}}\right)$. Phase $\mathrm{I}=$ anatomical dead space. Phase II = mixture of anatomical dead space and alveolar gas. Phase III = alveolar plateau. From Reference 102.

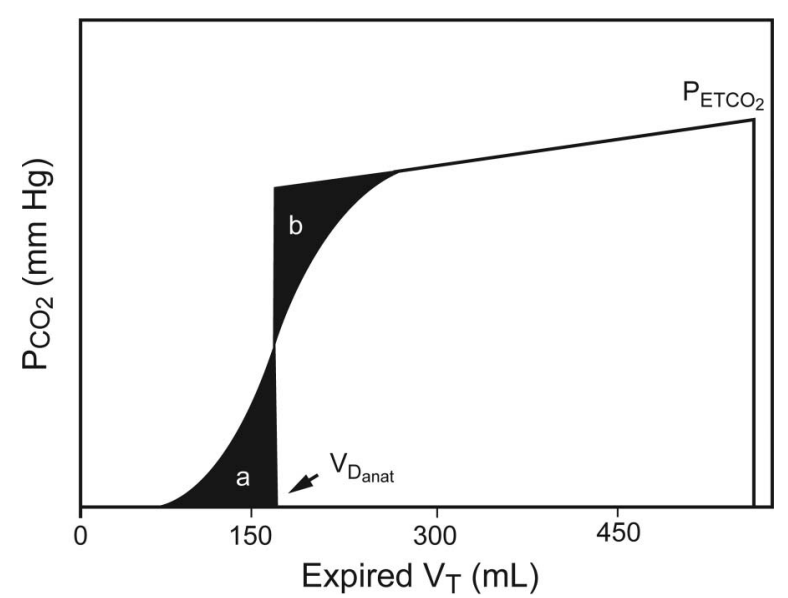

Fig. 5. Fowler's method for identifying anatomic dead space $\left(\mathrm{V}_{\text {Danat }}\right)$ in relation to the slope of phase $\mathrm{III}$ and the end-tidal $\mathrm{CO}_{2}\left(\mathrm{P}_{\mathrm{ETCO}}\right)$ on the volumetric capnogram, where phase II is divided into equal areas a and b. From References 103 and 104.

by computer analysis of the volumetric capnogram. ${ }^{104}$ The midpoint of phase 2 of the volumetric capnogram signifies the boundary between conducting airways and gasexchange airways (respiratory bronchioles). When phase 2 is dissected by a vertical line originating from a line superimposed on the incline of phase 3 , the intersection at the $\mathrm{x}$ axis such that the 2 areas on either side of the vertical line that are equal in area can be created. This point of intersection and equivalent areas is equal to the anatomic dead space volume on the volumetric capnogram (Fig. 5).

Anatomical dead space in male and female volunteers at rest was originally approximated to be 156 and $104 \mathrm{~mL}$, respectively. ${ }^{103}$ Since the conducting airways are distensible, the anatomic dead space volume can increase with maximal voluntary inspiratory lung volume ${ }^{103}$ and by the application of positive pressure. ${ }^{105}$ The application of PEEP up to $18 \mathrm{~cm} \mathrm{H}_{2} \mathrm{O}$ was shown to increase the anatomic dead space volume by an average of 5\%.105 This increase in the anatomical dead space volume causes an incremental increase in the total physiologic dead space. The ability to measure anatomical dead space by volumetric capnography enables the components of physiologic dead space to be partitioned by single-breath analysis.

\section{Single-Breath $\mathrm{CO}_{2}$ Analysis}

The single-breath $\mathrm{CO}_{2}$ waveform analysis builds upon identification of the Fowler anatomical dead space and enables extraction of additional information regarding ventilation efficiency and further analysis and study of physiologic dead space.

When the perpendicular line that identifies the anatomic dead space is drawn through the volumetric capnogram to the $\mathrm{x}$ axis, the point of intersection to this line from an additional line superimposed on phase 3 of the capnogram allows the component volumes in a exhaled tidal breath to be partitioned into anatomical $\mathrm{V}_{\mathrm{D}}$, alveolar $\mathrm{V}_{\mathrm{D}}$, and alveolar $\mathrm{V}_{\mathrm{T}}{ }^{106,107}$ (Fig. 6).

This dissection of the volumetric capnogram area allows further study of the various components and their relationships. For instance, alveolar $V_{D}$ and anatomical $V_{D}$ were both found to be indices of lung recruitment and overdistention, ${ }^{105}$ and the alveolar $\mathrm{V}_{\mathrm{D}}$ /alveolar $\mathrm{V}_{\mathrm{T}}$ ratio decreased or increased in parallel to a positive or negative response to PEEP with respect to oxygenation and shunt. ${ }^{108}$

Additionally, the classic sloping "shark's fin" shape and morphology of the time-based or volume-based volumetric capnogram can be a visual indication of $\dot{V} / \mathrm{Q}$ mismatch due to bronchospasm and airway obstruction ${ }^{14,109,110}$ (Fig. 7) and an elevated $V_{D} / V_{T}$ in patients with ARDS (Fig. 8).

\section{Measuring Physiologic Dead Space}

The traditional technique for bedside measurement of $\mathrm{V}_{\mathrm{D}} / \mathrm{V}_{\mathrm{T}}$ used the method of exhaled gas collection and analysis to measure the partial pressure of the mean expired $\mathrm{CO}_{2}\left(\mathrm{P}_{\overline{\mathrm{ECO}}}\right) \cdot{ }^{111,112}$ Advancements in technology introduced the use of metabolic analyzers ${ }^{113,114}$ and volumetric capnography to measure the $\mathrm{P}_{\overline{\mathrm{ECO}}} \cdot{ }^{115,116}$

The simplified bedside calculation of $\mathrm{V}_{\mathrm{D}} / \mathrm{V}_{\mathrm{T}}$ uses the Enghoff modification of the Bohr equation. ${ }^{117}$ The Enghoff equation differs from the original Bohr equation by the substitution of $\mathrm{P}_{\mathrm{aCO}_{2}}$ for the partial pressure of mixed alveolar $\mathrm{CO}_{2}\left(\mathrm{P}_{\mathrm{ACO}_{2}}\right) .{ }^{118}$ Since $\mathrm{P}_{\mathrm{ACO}_{2}}$ was difficult to accurately measure or estimate at the bedside, the Enghoff equation became the standard method for many years in 


\section{Monitoring Exhaled CARbon Dioxide}

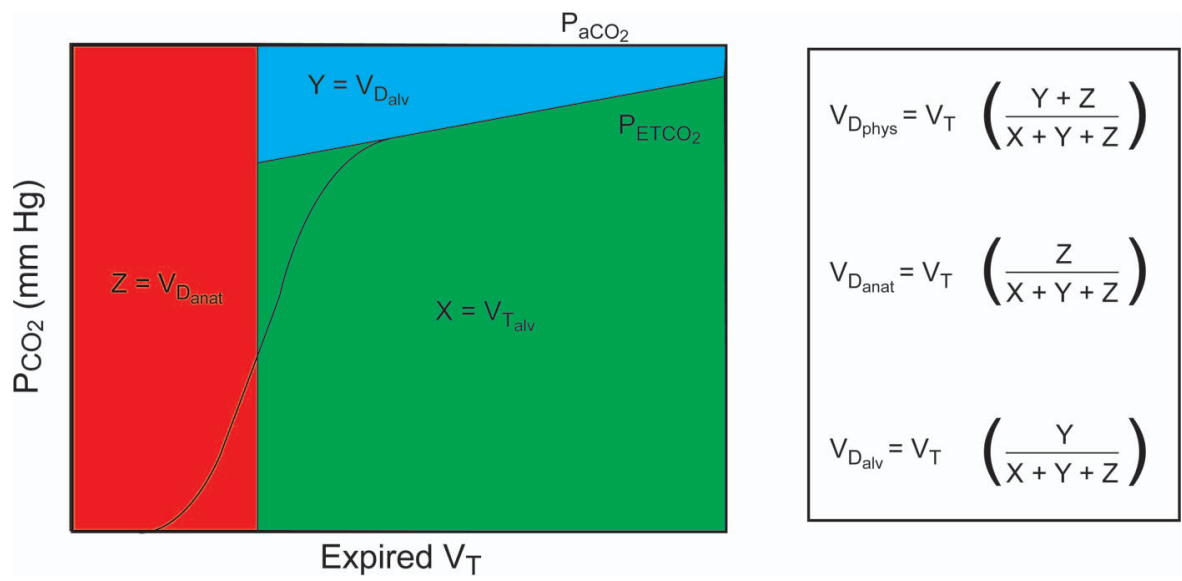

Fig. 6. Single-breath $\mathrm{CO}_{2}$ analysis further dissects the area of the volumetric capnogram and allows for the calculation of the alveolar dead space volume $\left(V_{\text {Dalv }}\right)$, anatomic dead space volume $\left(V_{\text {Danat }}\right)$, alveolar tidal volume $\left(V_{\text {Talv }}\right)$, and the physiologic dead space volume $\left(V_{\text {Dphys }}\right)$ in relation to $\mathrm{P}_{\mathrm{aCO}}$ and partial pressure of end-tidal $\mathrm{CO}_{2}\left(\mathrm{P}_{\mathrm{ETCO}}\right)$. From Reference 106, with permission.

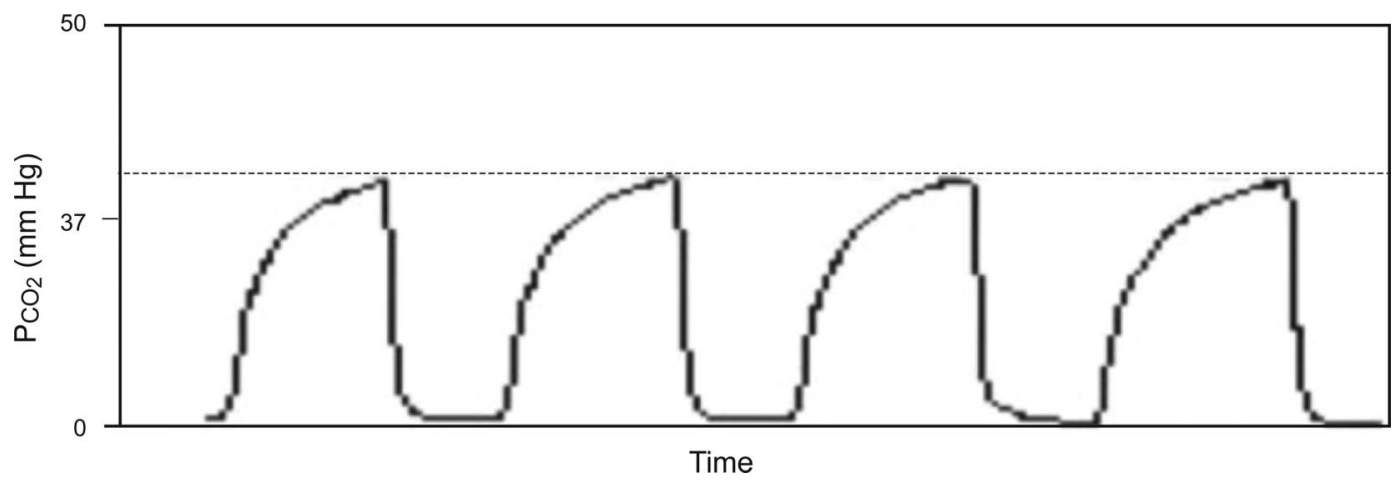

Fig. 7. A "shark's fin" time-based capnogram waveform showing severe airway obstruction. From Reference 14.

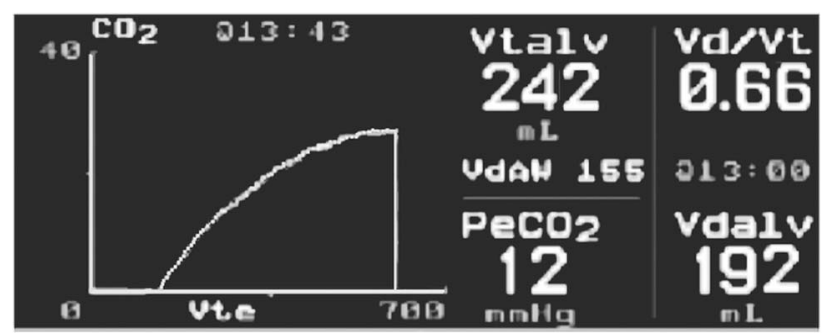

Fig. 8. A shark's fin volumetric capnogram of a patient diagnosed with ARDS with elevated dead-space fraction.

bedside clinical practice for calculation of $\mathrm{V}_{\mathrm{D}} / \mathrm{V}_{\mathrm{T}}$, where the Enghoff-Bohr equation is

$$
\mathrm{V}_{\mathrm{D}} / \mathrm{V}_{\mathrm{TEngh}}=\left(\mathrm{P}_{\mathrm{aCO}_{2}}-\mathrm{P}_{\overline{\mathrm{ECO}}}\right) / \mathrm{P}_{\mathrm{aCO}}
$$

and the original Bohr equation is

$$
\mathrm{V}_{\mathrm{D}} / \mathrm{V}_{\mathrm{TBohr}}=\left(\mathrm{P}_{\mathrm{ACO}_{2}}-\mathrm{P}_{\overline{\mathrm{E}}_{2}}\right) / \mathrm{P}_{\mathrm{ACO}_{2}} .
$$

In the past, $\mathrm{P}_{\overline{\mathrm{E} C O}}$ measurements using the gas collection bag method ${ }^{111,112}$ were cumbersome, time consuming, and error-prone and entailed collecting up to $30-60 \mathrm{~L}$ of expired gas for a mean $\mathrm{CO}_{2}$ sample measurement. Also, the gas collection bag method is no longer feasible due to the common presence of bias flow on current ventilators. The introduction of metabolic analyzers for the $\mathrm{P}_{\overline{\mathrm{ECO}}}$ measurement requires use of a correction for ventilator circuit compression volume ${ }^{116}$ and relies on the accurate measurement of the fraction of mean expired $\mathrm{CO}_{2}\left(\mathrm{~F}_{\overline{\mathrm{E} C O}}\right)$, whereby

$$
\mathrm{P}_{\overline{\mathrm{E} C O}}=\mathrm{F}_{\overline{\mathrm{E} C O}} \times\left(\mathrm{P}_{\mathrm{B}}-47\right) .
$$

$\left(\mathrm{P}_{\mathrm{B}}\right.$ represents barometric pressure, 47 is water vapor pressure at $37^{\circ} \mathrm{C}$ ) The introduction of the volumetric $\mathrm{CO}_{2}$ monitor has simplified the bedside measurement by continuously measuring $\mathrm{P}_{\overline{\mathrm{E} C O}}$, and allowing intermittent input of $\mathrm{P}_{\mathrm{aCO}_{2}}$ for the calculation of $\mathrm{V}_{\mathrm{D}} / \mathrm{V}_{\mathrm{T}} \cdot{ }^{115}$

$\mathrm{P}_{\overline{\mathrm{ECO}}_{2}}$ can also be derived from ventilator volumetric capnography measurements using $\dot{\mathrm{V}}_{\mathrm{CO}_{2}}$ and expired minute ventilation $\left(\dot{\mathrm{V}}_{\mathrm{E}}\right),{ }^{116}$ whereby 


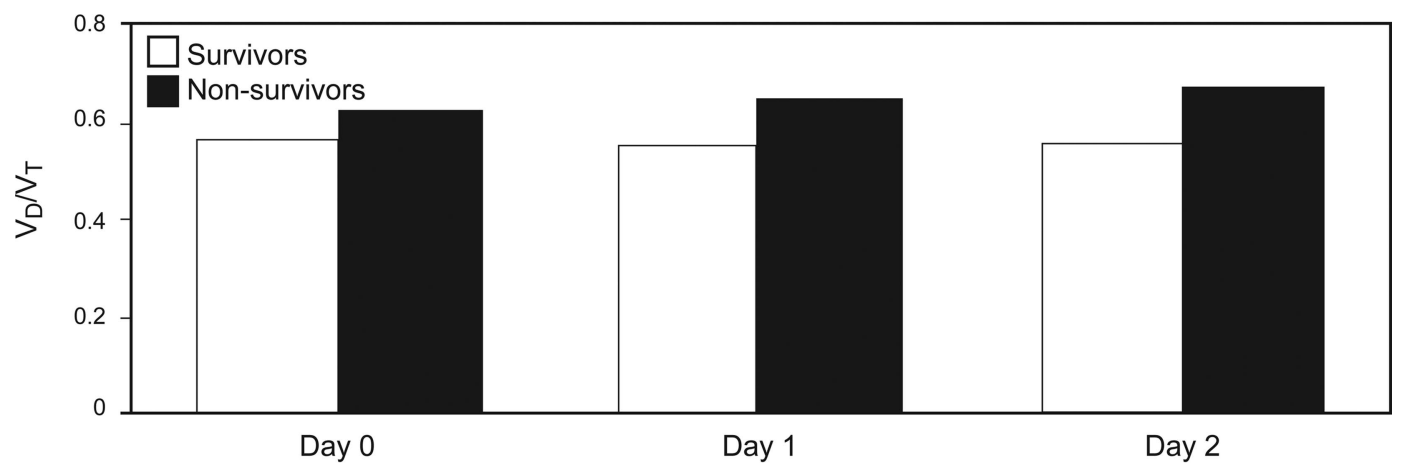

Fig. 9. Dead space/tidal volume $\left(V_{D} / V_{T}\right)$ in non-survivors compared with survivors was significantly higher on study day 1 and day 2 after diagnosis of ARDS. Data from Reference 131.

$$
\mathrm{F}_{\overline{\mathrm{E}} \mathrm{CO}_{2}}=\dot{\mathrm{V}}_{\mathrm{CO}_{2}} / \dot{\mathrm{V}}_{\mathrm{E}}
$$

By using Equation 3 to calculate $\mathrm{P}_{\overline{\mathrm{ECO}}}$, Equation 1 can then be used for the calculation of $\mathrm{V}_{\mathrm{D}} / \mathrm{V}_{\mathrm{T}} \cdot{ }^{116}$

\section{Clinical Usefulness of Physiologic Dead Space Measurements}

Measuring $\mathrm{V}_{\mathrm{D}} / \mathrm{V}_{\mathrm{T}}$ in the critically ill patient during mechanical ventilation is important for several reasons. The prognostic value of $\mathrm{V}_{\mathrm{D}} / \mathrm{V}_{\mathrm{T}}$ has been linked to the severity of lung injury and the risk of death in patients with ARDS. Furthermore, $\mathrm{V}_{\mathrm{D}} / \mathrm{V}_{\mathrm{T}}$ can be useful as an indicator of lung recruitment versus overdistention in patients with ARDS, may be helpful as a predictor of extubation success in adult and pediatric patients, and may be useful in assessing the severity and confirming the suspicion of pulmonary embolism.

\section{Assessing the Severity of Lung Injury}

$\mathrm{V}_{\mathrm{D}} / \mathrm{V}_{\mathrm{T}}$ is known to be a marker of the type ${ }^{119}$ and severity of lung injury during ARDS in regard to the degree of hypoxemia, ${ }^{120}$ histopathological changes, ${ }^{120,121} \dot{\mathrm{V}} / \mathbf{Q}$ defects, ${ }^{122,123}$ intrapulmonary shunt, ${ }^{119,123,124}$ and the need for supportive rescue therapies. ${ }^{19,124}$ Monitoring serial changes in $\mathrm{V}_{\mathrm{D}} / \mathrm{V}_{\mathrm{T}}$ over the course of critical illness in addition to other markers of disease severity is therefore warranted.

\section{Predicting Survival in ARDS Patients}

$\mathrm{V}_{\mathrm{D}} / \mathrm{V}_{\mathrm{T}}$ has been shown to be predictive of the mortality risk in patients with ARDS in both the early and intermediate phases of the disease. ${ }^{125-131}$ During the first $2 \mathrm{~d}$ following an ARDS diagnosis, $\mathrm{V}_{\mathrm{D}} / \mathrm{V}_{\mathrm{T}}$ was significantly higher among non-survivors ${ }^{131}$ (Fig. 9). Patients with $\mathrm{V}_{\mathrm{D}} / \mathrm{V}_{\mathrm{T}}=0.57$ were found to have higher mortality, with a $45 \%$ increase in the odds of dying for every 0.05 increase

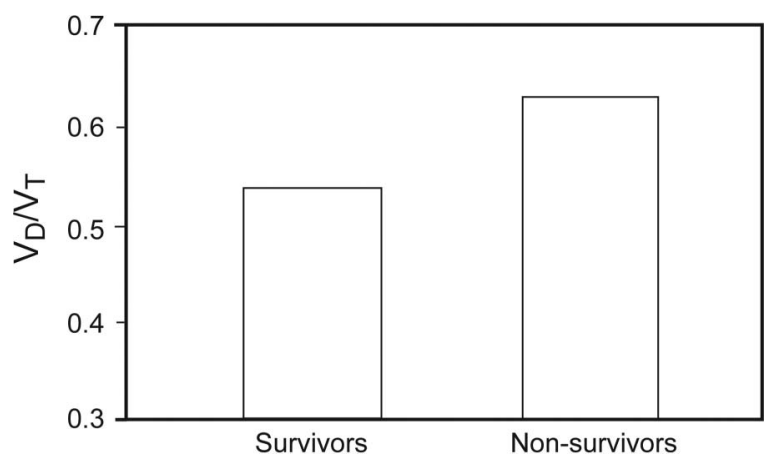

Fig. 10. Dead-space fraction differences (mean \pm SD) in ARDS survivors $(0.63 \pm 0.09)$ compared with non-survivors $(0.54 \pm 0.09)$ $(P<.001)$. Data from Reference 127.

in dead-space fraction. ${ }^{127}$ The mean dead-space fraction was also significantly higher in patients who died compared with those who survived (Fig. 10). Consequently, in the face of continually rising $\mathrm{V}_{\mathrm{D}} / \mathrm{V}_{\mathrm{T}}$ during the course of ARDS as a sign of possible futility, it may be appropriate to use this information to help guide plan of care decisions during critical illness.

\section{Indication of Lung Recruitment Versus Overdistention}

$\mathrm{V}_{\mathrm{D}} / \mathrm{V}_{\mathrm{T}}$ measurements in patients with ARDS have been found to be useful for titrating PEEP and optimizing cardiopulmonary function ${ }^{105,108,132}$ and may be useful as a tool to monitor lung recruitment versus overdistention. ${ }^{133-135}$

In one of the classic papers in critical care medicine published in 1975 , Suter et al ${ }^{105}$ demonstrated the value of measuring $\mathrm{V}_{\mathrm{D}} / \mathrm{V}_{\mathrm{T}}$ as a guide to optimizing gas exchange and pulmonary mechanics in patients with lung injury (Fig. 11). This early work has been repeatedly validated and therefore supports assessing and monitoring $\mathrm{V}_{\mathrm{D}} / \mathrm{V}_{\mathrm{T}}$ to assist with management decisions in patients with ARDS. 108,132,134,135 


\section{Monitoring Exhaled CARbon Dioxide}

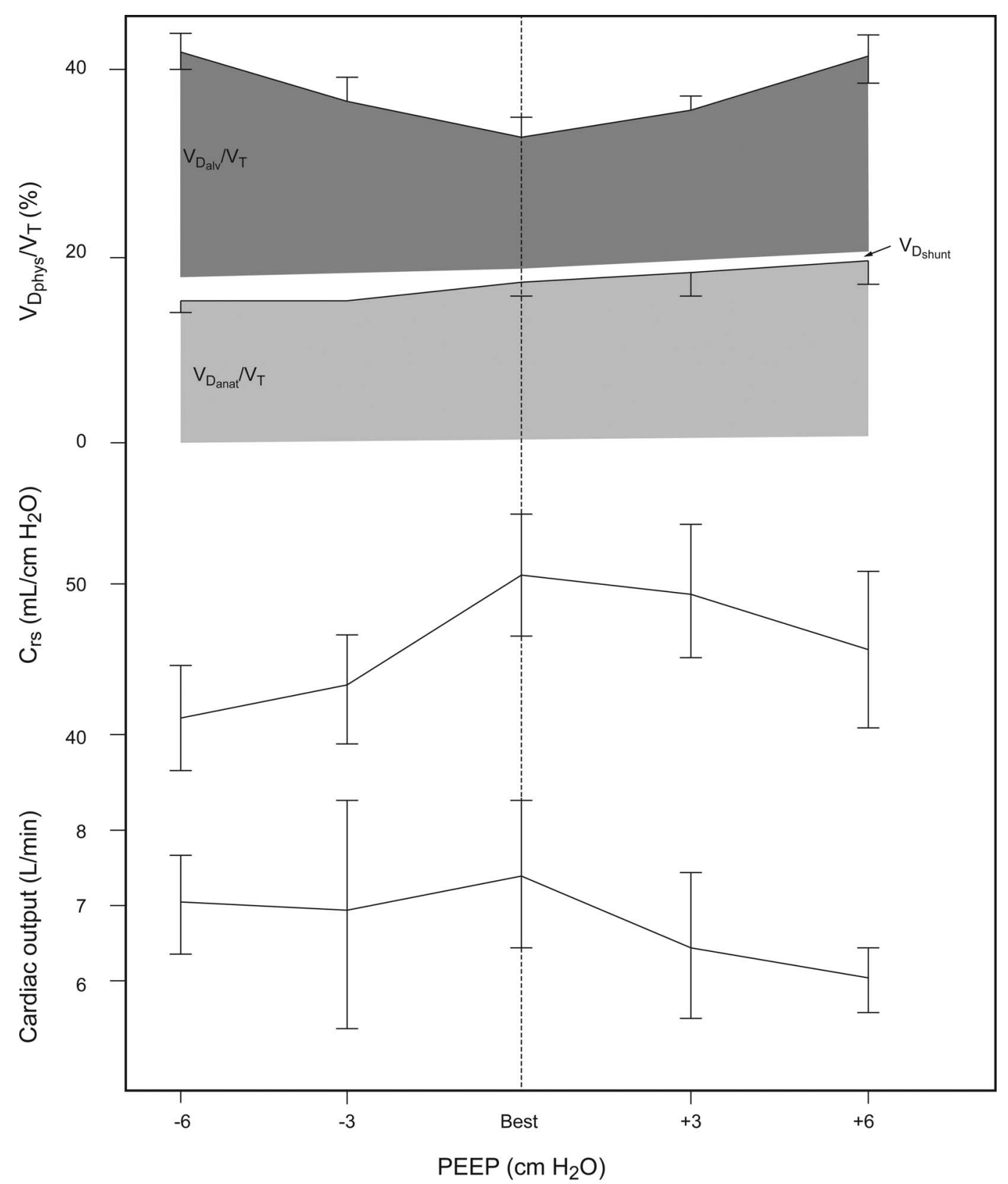

Fig. 11. Changes in physiologic dead space $\left(V_{\text {Dphys }} N_{T}\right)$, alveolar dead space $\left(V_{\text {Dalv }}\right)$, and anatomic dead space $\left(V_{\text {Danat }}\right)$ fraction, in relation to shunt $\left(V_{\text {Dshunt }}\right)$, total respiratory system compliance $\left(\mathrm{C}_{\mathrm{rs}}\right)$, cardiac output, and incremental changes in PEEP. From Reference 105, with permission.

\section{Predicting Successful Liberation From Mechanical Ventilation}

$\mathrm{V}_{\mathrm{D}} / \mathrm{V}_{\mathrm{T}}$ assessments may also be used to predict extubation success in pediatric ${ }^{136}$ and adult patients. ${ }^{137,138}$ Values for $\mathrm{V}_{\mathrm{D}} / \mathrm{V}_{\mathrm{T}} \leq 0.50$ and $\geq 0.65$ in infants and children were found to predict extubation success or failure $^{136}$ (Fig. 12), whereas in adult patients, the cutoff value for $\mathrm{V}_{\mathrm{D}} / \mathrm{V}_{\mathrm{T}}=0.58$ offered the best sensitivity and specificity for predicting extubation failure. ${ }^{137}$ It has also been suggested that elevated $\mathrm{V}_{\mathrm{D}} / \mathrm{V}_{\mathrm{T}}$ may be useful for predicting the need for noninvasive ventilation after extubation ${ }^{138}$ and therefore the potential for averting the need for re-intubation.

\section{Diagnosis of Pulmonary Embolism}

$\mathrm{V}_{\mathrm{D}} / \mathrm{V}_{\mathrm{T}}$, in addition to other clinical assessments and diagnostic tests, can be useful in excluding or diagnosing pulmonary embolism. $\mathrm{V}_{\mathrm{D}} / \mathrm{V}_{\mathrm{T}}>40 \%$ was found to be 


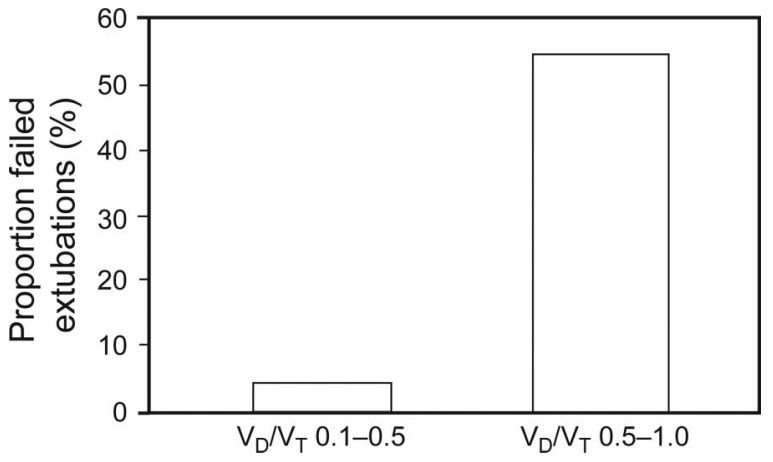

Fig. 12. Graph plotting the differences of physiologic dead space to tidal volume $\left(\mathrm{V}_{\mathrm{D}} / \mathrm{V}_{\mathrm{T}}\right)$ range against the percentage of subjects requiring additional ventilatory support after extubation. Data from Reference 136.

highly suggestive of pulmonary embolism and was comparable in terms of sensitivity and specificity with a lung perfusion scan. ${ }^{139}$ Assessment of the size of the capnogram waveform area was identified as a useful screening method for pulmonary embolism. When the capnogram area was low, signifying a larger $\mathrm{P}_{\mathrm{aCO}}$ to $\mathrm{P}_{\mathrm{ETCO}_{2}}$ difference, the presence of pulmonary embolism was more likely. ${ }^{140}$ Conversely, when $\mathrm{P}_{\mathrm{ETCO}_{2}}$ was normal $\left(>36 \mathrm{~mm} \mathrm{Hg}\right.$ ), the narrow $\mathrm{P}_{\mathrm{aCO}_{2}}-\mathrm{P}_{\mathrm{ETCO}_{2}}$ difference reliably excluded pulmonary embolism compared with contrast-enhanced helical computed tomography or ventilation/perfusion scan. ${ }^{141}$

The arterial to end-tidal alveolar dead space ratio $\left(\left[\mathrm{P}_{\mathrm{aCO}_{2}}\right.\right.$ $\left.-\mathrm{P}_{\mathrm{ETCO}_{2}}\right] / \mathrm{P}_{\mathrm{aCO}_{2}}$ ) cutoff value of $15 \%$ has also been shown to help exclude or confirm pulmonary embolism. ${ }^{141}$ When the alveolar $\mathrm{V}_{\mathrm{D}}$ /alveolar $\mathrm{V}_{\mathrm{T}}$ ratio is $<20 \%$, the probability of pulmonary embolism is low ${ }^{142-146}$ and was found to reduce the need for further diagnostic tests. ${ }^{148}$ On the other hand, an elevated alveolar $\mathrm{V}_{\mathrm{D}}$ /alveolar $\mathrm{V}_{\mathrm{T}}$ also predicts pulmonary embolism, the severity of the perfusion defect, and the degree of vascular occlusion. ${ }^{148}$

\section{Bohr Versus Enghoff Approach to Physiologic Dead Space Measurements}

The Bohr dead space equation relies on the calculation or estimation of $\mathrm{P}_{\mathrm{ACO}_{2}}$ from mixed alveolar gas and $\mathrm{P}_{\overline{\mathrm{ECO}}}$, which signifies the combined effect of the volume of anatomical $\mathrm{V}_{\mathrm{D}}$, alveolar $\mathrm{V}_{\mathrm{D}}$, and alveolar $\mathrm{V}_{\mathrm{T}} \cdot \mathrm{P}_{\mathrm{ACO}_{2}}$ is affected by the dilution of $\mathrm{CO}_{2}$ from the alveolar side of the alveolar-capillary membrane from gas exchange units with low or no perfusion. $\mathrm{P}_{\overline{\mathrm{ECO}}}$ is determined by the volume of $\mathrm{CO}_{2}$ excreted from the lungs $\left(\dot{\mathrm{V}}_{\mathrm{CO}_{2}}\right)$ compared with the total $\dot{\mathrm{V}}_{\mathrm{E}}$ (Equations 3 and 4). Bohr dead space is affected by areas of ventilation to perfusion inequality, such as during alveolar overdistention by excessive PEEP and/or $\mathrm{V}_{\mathrm{T}}$, occlusion of the pulmonary vasculature, and low pul- monary perfusion secondary to hypovolemia or shock. Bohr dead space is recognized as true dead space, or the balance between effective and ineffective ventilation occurring in the lungs ${ }^{149}$ (Fig. 13).

The Enghoff dead space equation, on the other hand, relies on the $\mathrm{P}_{\mathrm{aCO}_{2}}$ of arterial blood and is thus affected by global gas exchange inefficiency and the effects of shunt and venous admixture (Fig. 14). $\mathrm{P}_{\mathrm{aCO}_{2}}$ can be elevated from all sources of low ventilation to perfusion matching and shunt, such as atelectasis, pneumonia, COPD, and asthma. $\mathrm{P}_{\mathrm{aCO}_{2}}$ can also rise when an increase in metabolism and $\mathrm{CO}_{2}$ production is not accompanied by an increase in $\mathrm{CO}_{2}$ excretion. When $\dot{\mathrm{V}}_{\mathrm{CO}_{2}}$ increases without a proportional rise in alveolar ventilation, production of $\mathrm{CO}_{2}$ exceeds the rate of excretion, and $\mathrm{P}_{\mathrm{aCO}_{2}}$ increases. Therefore, it is important to understand that the Enghoff equation overestimates $V_{D} / V_{T}$ in the presence of shunt and low $\dot{\mathrm{V} / \mathrm{Q}}$.

The determination of $\mathrm{P}_{\mathrm{ACO}_{2}}$ using volumetric capnography for the calculation of Bohr dead space has been demonstrated by mathematical modeling. ${ }^{152}$ and measured in an animal model of lung injury. ${ }^{153} \mathrm{P}_{\mathrm{ACO}_{2}}$ calculated from the phase 3 midpoint of the volume capnogram was compared with the $\mathrm{P}_{\mathrm{ACO}_{2}}$ derived mathematically using the multiple-inert gas elimination technique. This demonstrated a close linear correlation between the 2 methods for $\mathrm{P}_{\mathrm{ACO}_{2}}$ calculation $(\mathrm{r}=0.99, P<.001)$ and Bohr dead space $(\mathrm{r}=0.96, P<.001)$. The Bohr dead space and the mean $\mathrm{P}_{\mathrm{ACO}_{2}}$ from volumetric capnography were similar to the multiple-inert gas elimination technique calculations, with a mean bias of $10 \mathrm{~mL}(95 \% \mathrm{CI}-44$ to $64 \mathrm{~mL})$ and $-0.10 \mathrm{~mm} \mathrm{Hg}$ (95\% CI -2.18 to $1.98 \mathrm{~mm} \mathrm{Hg}$ ), respectively.

The ability to measure $\mathrm{P}_{\mathrm{ACO}_{2}}$ from the volumetric capnogram and therefore enabling the calculation of Bohr dead space has several significant implications. Measurement of Bohr dead space returns a more accurate reflection of effective and ineffective ventilation and perfusion in the lungs that is not impacted by the effects of shunt and low $\dot{\mathrm{V}} / \dot{\mathrm{Q}}$ on $\mathrm{P}_{\mathrm{aCO}_{2}}$ (Fig. 15).

The effects of shunt on the measurement of $\mathrm{V}_{\mathrm{D}} / \mathrm{V}_{\mathrm{T}}$ was investigated using a computer model simulation that controlled for variations of $\mathrm{P}_{\mathrm{ACO}}$, alveolar $\mathrm{V}_{\mathrm{D}}$, anatomical $\mathrm{V}_{\mathrm{D}}$, pulmonary shunt, and $\dot{\mathrm{V}} / \mathrm{Q}$ ratio distribution ${ }^{154}$ (Fig. 16) and in a lung lavage animal model using the midpoint of phase 3 to define $\mathrm{P}_{\mathrm{ACO}_{2}}{ }^{155}$ (Fig. 17). Both experiments confirmed that increasing levels of shunt and low $\dot{V} / \mathrm{Q}$ markedly affects dead space values calculated by Enghoff's (Equation 1) but not Bohr's equation (Equation 2).

An estimate of the Bohr dead space can also be calculated by substituting $\mathrm{P}_{\mathrm{ETCO}}$ for $\mathrm{P}_{\mathrm{ACO}_{2}}$, whereby the Bohr estimate equation is 


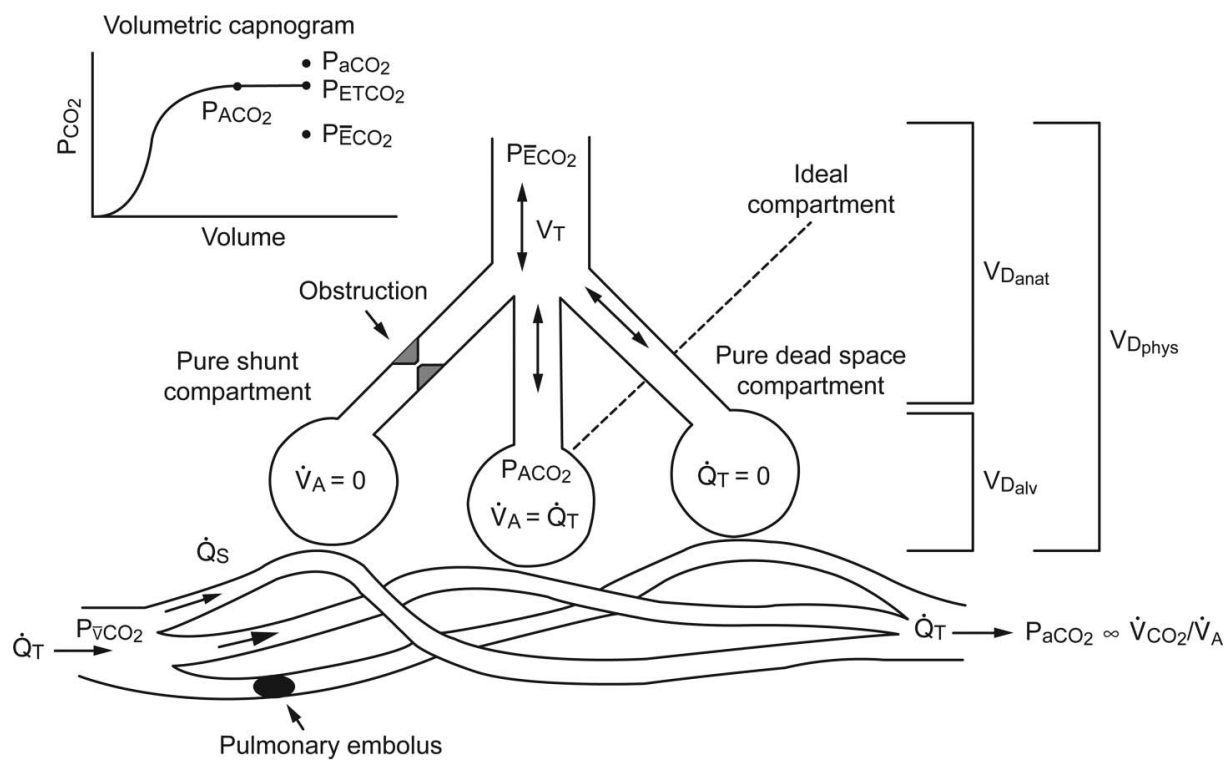

Fig. 13. The 3-compartment lung model described by Riley and Cournand151,152 represents gas exchange in the lung in regard to the matching of alveolar gas volume $\left(\dot{\mathrm{V}}_{\mathrm{A}}\right)$ and perfusion $\left(\dot{\mathrm{Q}}_{\mathrm{T}}\right)$, shunt $\left(\dot{\mathrm{Q}}_{\mathrm{S}}\right)$, and dead space $\left(\mathrm{V}_{\mathrm{D}}\right)$. The ideal compartment represents areas of perfect alveolar gas volume to $\dot{Q}_{T}$ matching. The pure shunt compartment represents areas of perfusion without ventilation. The pure dead-space compartment represents areas of ventilation with no perfusion. The sum of the regions of alveolar dead space $\left(V_{\text {Dalv }}\right)$ and anatomic dead space $\left(V_{\text {Danat }}\right)$ equal the physiologic dead space $\left(V_{\text {Dphys }}\right)$. The dead space fraction is equal to $V_{\text {Dphys }}$ divided by tidal volume $\left(V_{T}\right)$. Also shown are $\mathrm{P}_{\mathrm{aCO}}$, the partial pressure of venous carbon dioxide $\left(\mathrm{P}_{\mathrm{vCO}_{2}}\right)$, the relationship between $\mathrm{P}_{\mathrm{aCO}}$ and minute $\mathrm{CO}_{2}$ production $\left(\dot{V}_{\mathrm{CO}_{2}}\right)$ and alveolar gas volume, the partial pressure of mixed alveolar carbon dioxide $\left(\mathrm{P}_{\mathrm{ACO}}\right)$, the partial pressure of end-tidal carbon dioxide $\left(\mathrm{P}_{\mathrm{ETCO}}\right)$, and the $\mathrm{P}_{\mathrm{ECO}_{2}}$ in relation to the model and the volumetric capnogram. From Reference 116.

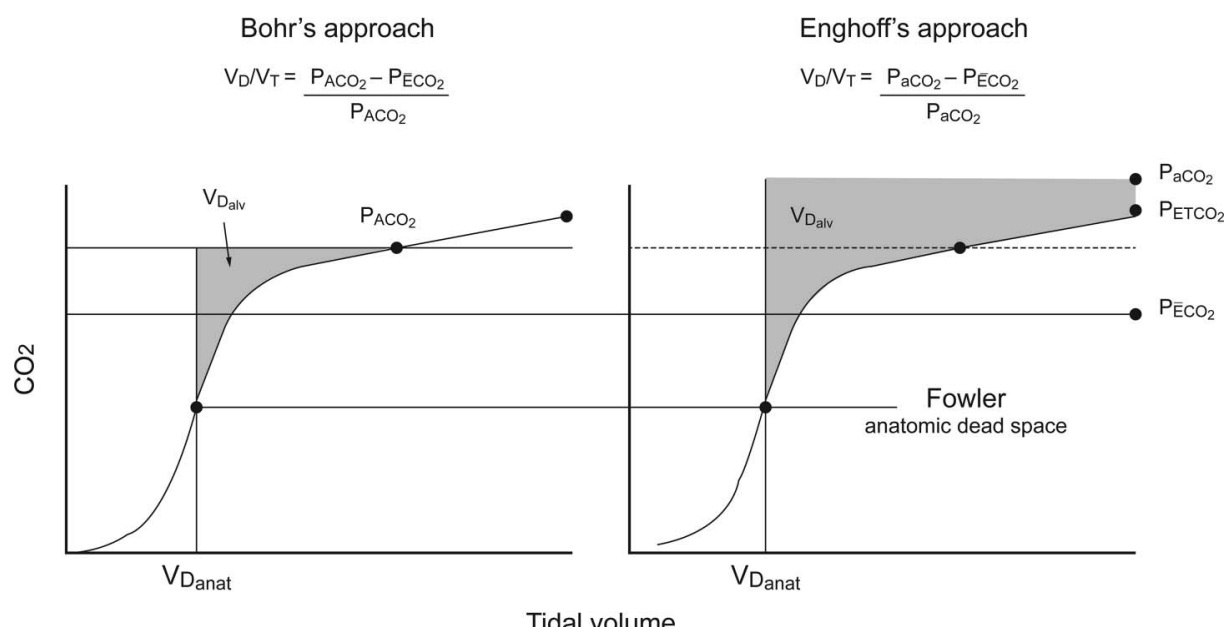

Tidal volume

Fig. 14. Graphical representation of physiologic dead space fraction determined by volumetric capnography, using the approaches of Bohr and Enghoff, which shows how use of the Enghoff equation can overestimate alveolar dead space $\left(V_{\text {Dalv }}\right)$ (shaded areas) by substitution of the $\mathrm{P}_{\mathrm{aCO}}$ for the partial pressure of mixed alveolar carbon dioxide $\left(\mathrm{P}_{\mathrm{ACO}_{2}}\right)$, determined by identifying the midpoint of phase III of the expired volumetric capnogram. ${ }^{153,154}$ Also shown are the airway or anatomical dead space $\left(\mathrm{V}_{\text {Danat }}\right.$; determined by the Fowler method identified at the midpoint of phase II of the expired volumetric capnogram), ${ }^{103}$ the partial pressure of end-tidal carbon dioxide $\left(\mathrm{P}_{\mathrm{ETCO}}\right)$, and the partial pressure of mean expired carbon dioxide $\left(\mathrm{P}_{\mathrm{E}_{\mathrm{CO}}}\right)$ in relation to the volumetric capnogram. ${ }^{150}$ From Reference 116.

$$
\mathrm{V}_{\mathrm{D}} / \mathrm{V}_{\mathrm{TBohr}} \mathrm{Est}=\left(\mathrm{P}_{\mathrm{ETCO}_{2}}-\mathrm{P}_{\overline{\mathrm{E}}_{2}}\right) / \mathrm{P}_{\mathrm{ETCO}_{2}} \text {. }
$$

The comparison of $\mathrm{V}_{\mathrm{D}} / \mathrm{V}_{\text {TEngh }}, \mathrm{V}_{\mathrm{D}} / \mathrm{V}_{\mathrm{TBohr}}$, and $\mathrm{V}_{\mathrm{D}} / \mathrm{V}_{\mathrm{TBohr}}$ Est in regard to the area representing anatomical
$\mathrm{V}_{\mathrm{D}}$ and alveolar $\mathrm{V}_{\mathrm{D}}$ on the volumetric capnogram is depicted in Figure 18. Example calculations based on the different equations in relation to the volumetric capnogram are shown in Figure 19. 
Figures 18 and 19 demonstrate that the Enghoff equation overestimates true $\mathrm{V}_{\mathrm{D}} / \mathrm{V}_{\mathrm{T}}$. Using the Bohr estimate equation also overestimates $V_{D} / V_{T}$, but this difference will always be closer to the true Bohr dead space than the Enghoff equation, whether $\mathrm{V}_{\mathrm{D}} / \mathrm{V}_{\mathrm{T}}$ is normal or elevated. Although identifying $\mathrm{P}_{\mathrm{ACO}}$ from the midpoint of phase 3 of the volumetric capnogram is technically achievable, using the Bohr estimate equation and substituting $\mathrm{P}_{\mathrm{ETCO}_{2}}$ for $\mathrm{P}_{\mathrm{ACO}_{2}}$ would simplify the calculation, especially when the midpoint of phase 3 is not clearly identifiable.

Since $\mathrm{P}_{\overline{\mathrm{ECO}}}$ can be calculated using Equation 4, and $\mathrm{P}_{\mathrm{ETCO}_{2}}$ is available during volumetric $\mathrm{CO}_{2}$ monitoring, the continuous measurement of $\mathrm{V}_{\mathrm{D}} / \mathrm{V}_{\mathrm{TBoh}}$ Est is technically feasible and would eliminate the requirement of periodic arterial blood gas sampling to measure $\mathrm{P}_{\mathrm{aCO}_{2}}$ for $\mathrm{V}_{\mathrm{D}} / \mathrm{V}_{\mathrm{T}}$ calculation. The clinical value of constant monitoring and trending of $\mathrm{V}_{\mathrm{D}} / \mathrm{V}_{\text {TBohr Est }}$ during mechanical ventilation of the critically ill patient requires further investigation.

It has also been suggested that simultaneous assessment of Enghoff and Bohr dead space using volumetric capnog-

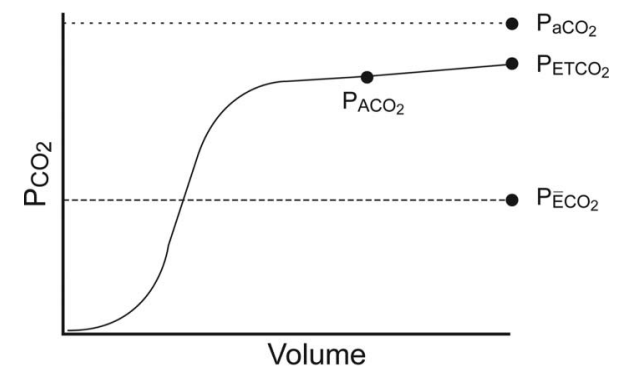

Fig. 15. Volumetric capnogram showing the relationship between $\mathrm{P}_{\mathrm{aCO}_{2}}$, the partial pressure of mixed alveolar carbon dioxide $\left(\mathrm{P}_{\mathrm{ACO}_{2}}\right)$, the partial pressure of end-tidal carbon dioxide $\left(\mathrm{P}_{\mathrm{ETCO}}\right)$, and the partial pressure of mean expired carbon dioxide $\left(\mathrm{P}_{\mathrm{E} \mathrm{CO}_{2}}\right)$.

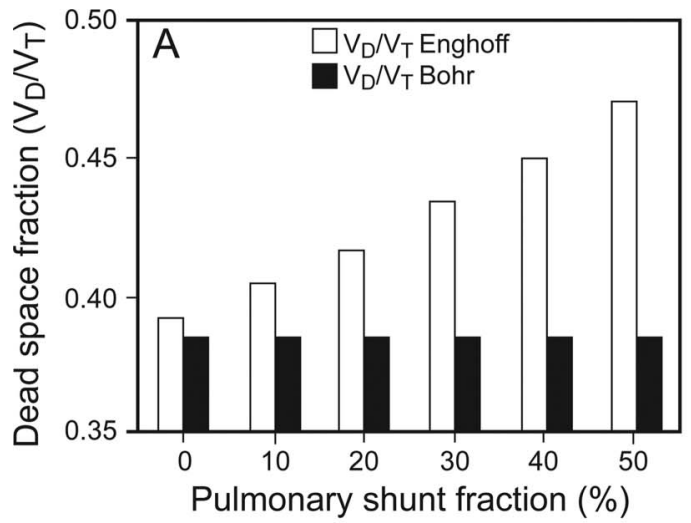

raphy may be useful in regard to recognizing the effects of shunt and $\dot{V} / \mathbf{Q}$ inequality versus true dead space or wasted ventilation in critically ill patients with elevated $\mathrm{V}_{\mathrm{D}} / \mathrm{V}_{\mathrm{T}} \cdot{ }^{149}$ Since many studies that identified $\mathrm{V}_{\mathrm{D}} / \mathrm{V}_{\mathrm{T}}$ as a predictor of outcome, disease diagnosis, and disease severity used the Enghoff equation, ${ }^{125-131,136-138,141-148}$ the conclusions of these studies may need to be reexamined using this new approach.

\section{Estimating Metabolic Rate and Resting Energy Expenditure}

Estimation of metabolic rate can be accomplished by $\dot{\mathrm{V}}_{\mathrm{CO}_{2}}$ measurements from volumetric capnography. The Weir equation is the accepted standard used during metabolic testing for calculating the nutritional support requirements in critically ill patients. Modifications to the Weir equation can be used to calculate resting energy expenditure (REE) by deriving a value for $\dot{\mathrm{V}}_{\mathrm{O}_{2}}$ adjusted for a normal respiratory quotient (RQ) based on a measurement of $\dot{V}_{\mathrm{CO}_{2}}$. The REE by the Weir equation and the REE based on $\dot{\mathrm{V}}_{\mathrm{CO}_{2}}\left(\right.$ REE-CO $\left.{ }_{2}\right)$ can be calculated, where

$$
\mathrm{REE}=\left(3.9 \times \dot{\mathrm{V}}_{\mathrm{O}_{2}}\right)+\left(1.1 \times \dot{\mathrm{V}}_{\mathrm{CO}_{2}}\right) \times 1.44
$$

and

$$
\text { REE-CO } \mathrm{CO}_{2}=\left(3.9 \times \dot{\mathrm{V}}_{\mathrm{CO}_{2}} / .85\right)+\left(1.1 \times \dot{\mathrm{V}}_{\mathrm{CO}_{2}}\right) \times 1.44
$$

When the actual RQ is equal to 0.85 , the REE- $\mathrm{CO}_{2}$ calculation results in an REE value equivalent to the value calculated by the standard Weir equation. The CCM Ex-

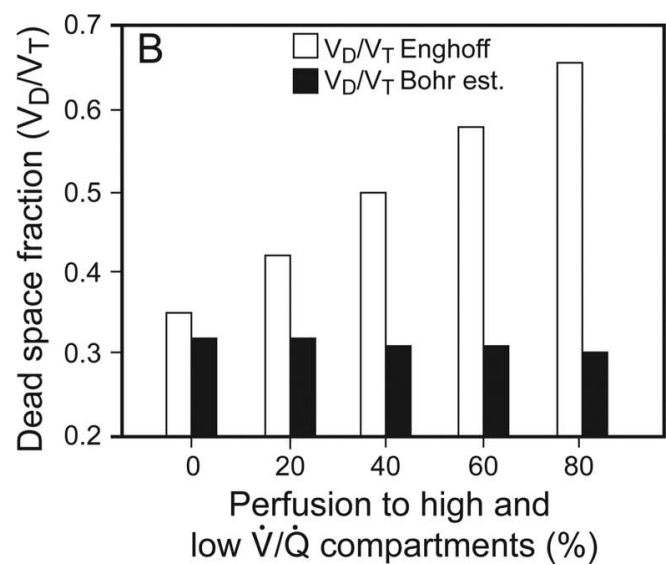

Fig. 16. Dead-space $\left(V_{D} / V_{T}\right)$ calculations using a mathematical computer model of the cardiorespiratory system. A: The effects of pulmonary shunt. B: The effects of pulmonary perfusion of high and low $\dot{V} / \dot{Q}$ compartments. $V_{D} / V_{T E n g h}$ is the dead-space calculated by using Enghoff's modification of the Bohr equation (Equation 1). $\mathrm{V}_{\mathrm{D}} / \mathrm{V}_{\mathrm{TB} \text { ohr }}$ is the dead space calculated by using the Bohr equation (Equation 2). $\mathrm{V}_{\mathrm{D}} / \mathrm{V}_{\mathrm{TB}}$ ohr est is the dead space calculated by using the Bohr estimate equation, which substitutes the partial pressure of end-tidal carbon dioxide $\left(\mathrm{P}_{\mathrm{ETCO}}\right)$ for the partial pressure of mixed alveolar carbon dioxide $\left(\mathrm{P}_{\mathrm{ACO}_{2}}\right)$ (Equation 5). Data from Reference 154. 


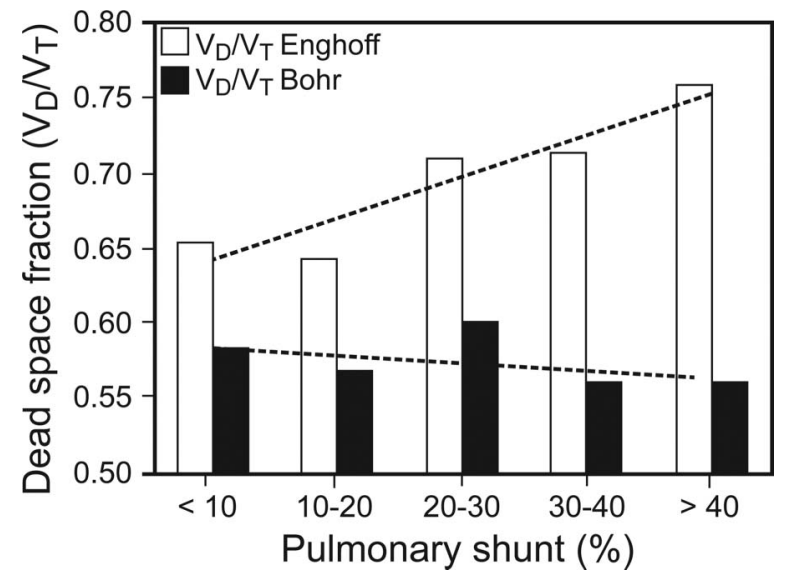

Fig. 17. Ratio of dead space to tidal volume $\left(V_{D} / V_{T}\right)$ stratified according to the level of shunt in a surfactant-depleted swine model induced by repeated lung lavage. $V_{D} / V_{\text {TEngh }}$ is calculated by Enghoff's modification of the Bohr equation (Equation 1). $V_{D} / V_{\text {TBohr }}$ is calculated by Bohr's dead-space equation (Equation 2). Dashed trend lines show that the difference between $V_{D} / V_{\text {TEngh }}$ and $V_{D} / V_{\text {TBohr }}$ increases as pulmonary shunt increases. Data from Reference 155 .

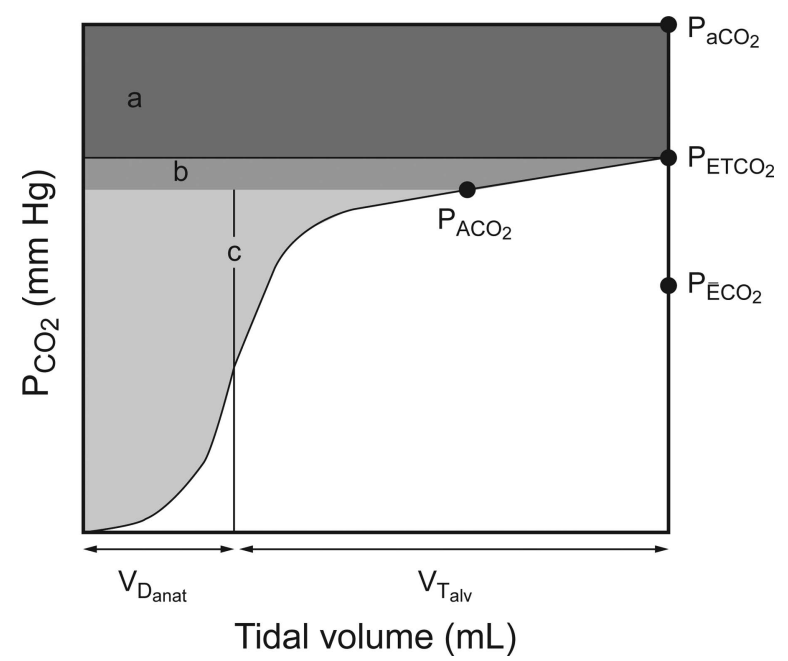

Fig. 18. Areas on the volumetric capnogram (in gray) representing the contribution of alveolar dead space to total physiologic dead space using $\mathrm{P}_{\mathrm{acO}}$ (area $\mathrm{a}+\mathrm{b}+\mathrm{c}$ ), the partial pressure of end tidal carbon dioxide $\left(\mathrm{P}_{\mathrm{ETCO}}\right)$ (area $\mathrm{b}+\mathrm{c}$ ), or the partial pressure of mixed alveolar carbon dioxide $\left(\mathrm{P}_{\mathrm{ACO}_{2}}\right)$ (area $\mathrm{c}$ ) in relation to the partial pressure of mean expired carbon dioxide $\left(\mathrm{P}_{\overline{\mathrm{E}} \mathrm{CO}_{2}}\right)$, the anatomic dead space volume $\left(\mathrm{V}_{\text {Danat }}\right)$, and the alveolar tidal volume $\left(\mathrm{V}_{\text {Talv }}\right)$.

press metabolic analyzer (Medical Graphics Corporation, St Paul, Minnesota) uses Equation 7 to calculate REE- $\mathrm{CO}_{2}$ with an accuracy of approximately $\pm 10 \%$ compared with the REE. ${ }^{156}$ The REE measured by the CCM Express using the standard Weir method was compared retrospectively with the REE- $\mathrm{CO}_{2}$ calculation in 67 adult ICU patients. ${ }^{157}$ The correlation coefficient $r=0.99$ and the coefficient of determination $r^{2}=0.98$, with bias and precision between measurements of $-15 \pm 126 \mathrm{cal} / \mathrm{d}$. When

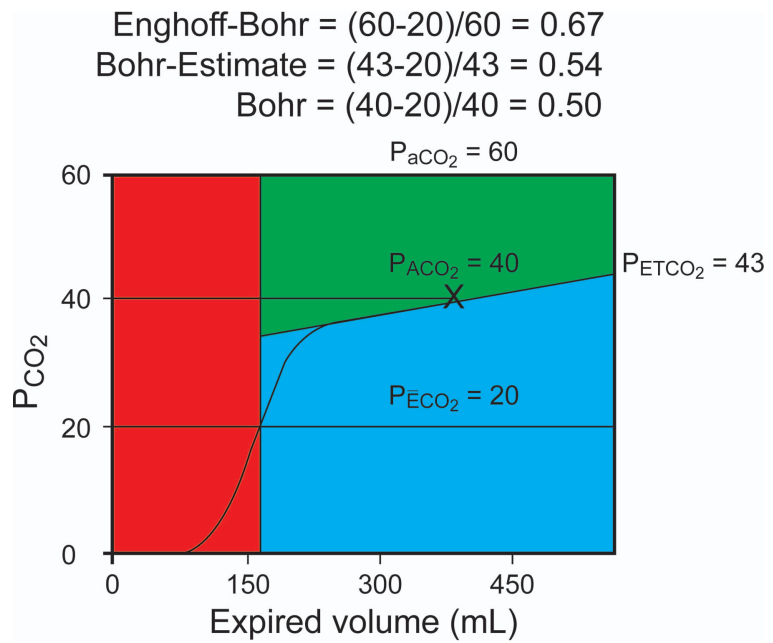

Fig. 19. Example calculations based on the different equations in relation to the volumetric capnogram.

the differences between REE and REE- $\mathrm{CO}_{2}$ were compared with the measured RQ, as the value for RQ moved toward 0.70 , the percentage error (mean bias/mean REE for the range of RQ) became more positive, and as RQ moved toward 1.0, the percentage error became more negative. Furthermore, when RQ was normal in the range between 0.80 and 0.90 , the average error was approximately $\pm 5 \%$ (Fig. 20). ${ }^{157}$

It should be noted that when using this approach, if the $\dot{\mathrm{V}}_{\mathrm{CO}_{2}}$ measuring device has a substantial bias and precision difference from measurements by a metabolic analyzer, additional variance between REE and REE- $\mathrm{CO}_{2}$ will result. This difference in measurement accuracy can be compensated for by use of a measurement bias correction.

The REE- $\mathrm{CO}_{2}$ equation can be further simplified by solving the equation with any combination of $\dot{\mathrm{V}}_{\mathrm{CO}_{2}}$ and $\dot{\mathrm{V}}_{\mathrm{O}_{2}}$ that equals an RQ of 0.85 , and dividing the calculated REE by the measured $\dot{\mathrm{V}}_{\mathrm{CO}_{2}}$, a single factor can be derived for calculating REE- $\mathrm{CO}_{2}$, whereby

$$
\text { REE- }-\mathrm{CO}_{2}=8.19 \times \dot{\mathrm{V}}_{\mathrm{CO}_{2}} \text {. }
$$

For example, when $\dot{\mathrm{V}}_{\mathrm{CO}_{2}}=221 \mathrm{~mL} / \mathrm{min}$ and $\dot{\mathrm{V}}_{\mathrm{O}_{2}}=260 \mathrm{~mL} / \mathrm{min}, \mathrm{RQ}=221 / 260=0.85$, and the Weir equation returns a calculated REE of $1,810 \mathrm{kcal} / \mathrm{d}$, whereby

$\operatorname{REE}=(3.9 \times 260)+(1.1 \times 221) \times 1.44=1,810 \mathrm{kcal} / \mathrm{d}$.

REE- $\mathrm{CO}_{2}$ can be calculated as follows:

$$
\begin{array}{r}
\text { REE-CO }{ }_{2}=[3.9 \times(221 / 0.85)+(1.1 \times 221) \times 1.44 \\
=1,810 \mathrm{kcal} / \mathrm{d}
\end{array}
$$




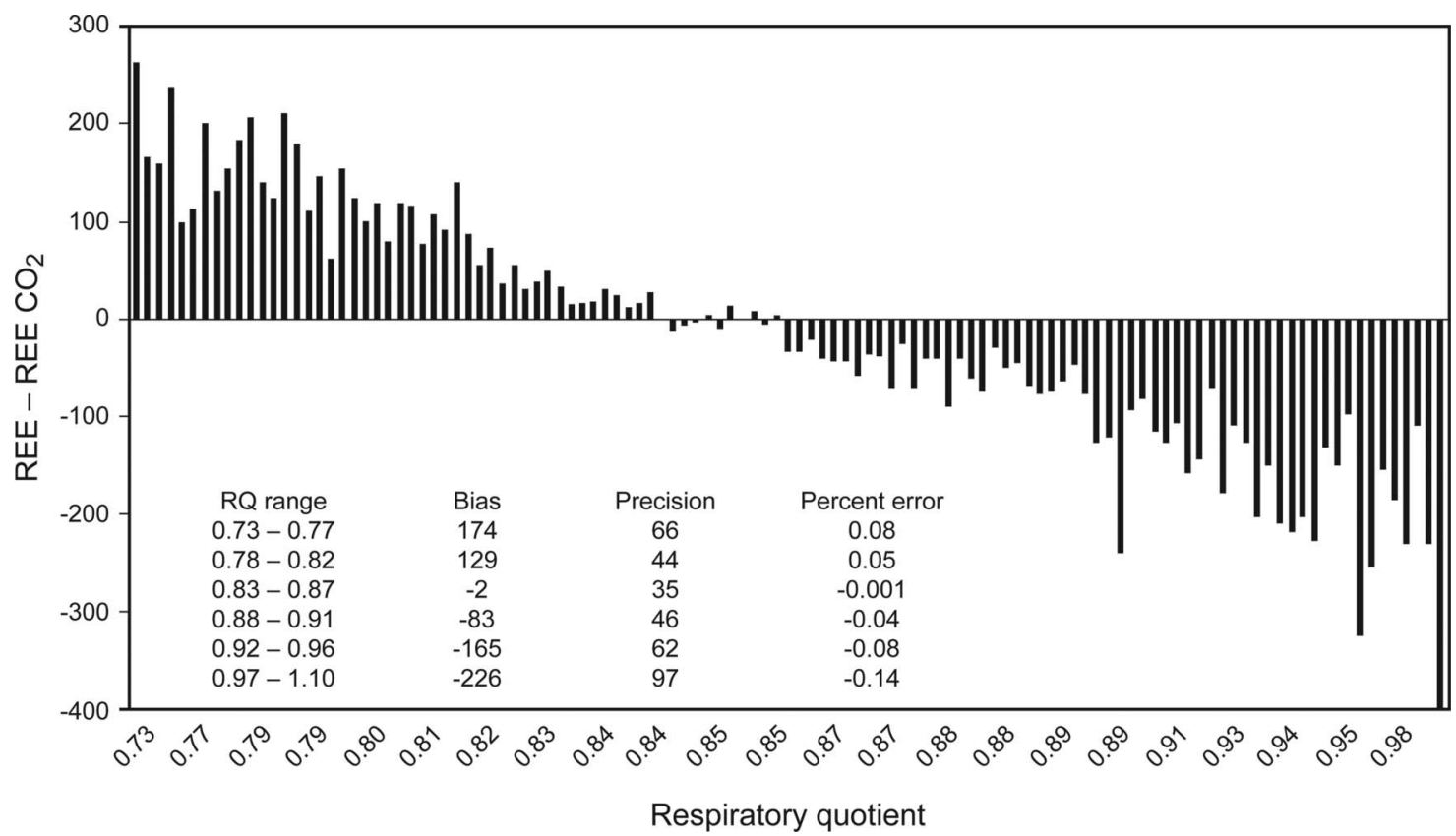

Fig. 20. Comparison of the differences between resting energy expenditure (REE) and resting energy expenditure based on $\dot{\mathrm{V}}_{\mathrm{CO}_{2}}\left(\mathrm{REE}-\mathrm{CO}_{2}\right)$ to the measured respiratory quotient (RQ). From Reference 157.

Table 2. Caloric Equivalent of Oxygen and Carbon Dioxide in Relation to the Respiratory Quotient and Nutritional Substrate 9,158

\begin{tabular}{lccc}
\hline \hline Substrate & $\begin{array}{c}\text { Respiratory } \\
\text { Quotient }\end{array}$ & $\begin{array}{c}\text { Oxygen Caloric } \\
\text { Equivalent (kcal/L) }\end{array}$ & $\begin{array}{c}\text { Carbon Dioxide } \\
\text { Caloric Equivalent } \\
(\mathrm{kcal} / \mathrm{L})\end{array}$ \\
\hline Carbohydrate & 1.0 & 5.05 & 5.05 \\
Mixed & 0.90 & 4.83 & 5.52 \\
Protein & 0.80 & 4.46 & 5.57 \\
Fat & 0.71 & 4.74 & 6.67 \\
\hline
\end{tabular}

and

$$
\mathrm{REE}-\mathrm{CO}_{2}=8.19 \times 221=1,810 \mathrm{kcal} / \mathrm{d}
$$

The caloric equivalence and carbon dioxide and oxygen can also be used to indirectly calculate REE from measurements of $\dot{\mathrm{V}}_{\mathrm{CO}_{2}}$ (Table 2). ${ }^{158-160}$ When the RQ $=0.90$, the $\mathrm{CO}_{2}$ caloric equivalent factor equals $5.52 \mathrm{kcal} / \mathrm{L}$, where

$$
\text { REE- } \mathrm{CO}_{2} \text { equivalent }=5.52 \times \dot{\mathrm{V}}_{\mathrm{CO}_{2}} \times 1.44
$$

This technique was compared with the Harris-Benedict calculation and the Weir equation. The Harris-Benedict equation significantly underestimated REE, but there was no significant difference between the Weir and REE- $\mathrm{CO}_{2}$

Table 3. Comparison of 4 Methods to Determine Basal Energy Expenditure or Resting Energy Expenditure ${ }^{158}$

\begin{tabular}{lcc}
\hline \hline \multicolumn{1}{c}{ Method } & Mean & SD \\
\hline BEE by Harris-Benedict equation, kcal/d & 1,716 & 225 \\
REE by Weir equation, kcal/d & 2,755 & 969 \\
REE by $\mathrm{O}_{2}$ caloric equivalent, kcal/d & 2,712 & 971 \\
REE by $\mathrm{CO}_{2}$ caloric equivalent, kcal/d & 2,677 & 854 \\
& & \\
BEE $=$ basal energy expenditure & & \\
REE $=$ resting energy expenditure & & \\
\end{tabular}

equivalent calculation ${ }^{158}$ (Table 3 ). Because of the technical difficulty of measuring $\dot{\mathrm{V}}_{\mathrm{O}_{2}}$, the REE- $\mathrm{CO}_{2}$ equivalent calculation is simpler and should be the preferred method, especially when the $\mathrm{F}_{\mathrm{IO}_{2}}$ is $>0.60 .{ }^{159}$

The ability to perform metabolic measurements using $\dot{\mathrm{V}}_{\mathrm{CO}_{2}}$ from volumetric capnography has several important implications. $\dot{\mathrm{V}}_{\mathrm{CO}_{2}}$ measurement capabilities are increasingly more available on standalone monitors and ventilators. This makes estimates of REE more readily accessible when metabolic analyzers are not available. When $\dot{\mathrm{V}}_{\mathrm{CO}_{2}}$ is being monitored either continuously or intermittently during mechanical ventilation, if the $\mathrm{REE}-\mathrm{CO}_{2}$ calculation is incorporated into the ventilator, estimates of the metabolic rate and nutritional requirements could be available in real time and trended over the course of critical illness. ${ }^{9}$

Additionally, since $\mathrm{F}_{\mathrm{IO}_{2}}$ does not affect the accuracy of the REE- $\mathrm{CO}_{2}$ calculation, $\mathrm{F}_{\mathrm{IO}_{2}}>0.60$ may no longer be a limitation of measuring a reasonable estimate of REE. The 


\section{Monitoring Exhaled CARbon Dioxide}

implications of using the REE- $\mathrm{CO}_{2}$ calculations are significant in that even the most severe critically ill patients receiving mechanical ventilation receiving $100 \%$ oxygen and high levels of PEEP can have REE estimates performed to manage their complex nutritional needs.

Since volumetric capnography and $\dot{\mathrm{V}}_{\mathrm{CO}_{2}}$ monitoring are becoming more readily available and are less costly than traditional metabolic testing, their use should be considered for incorporation into a standard nutrition assessment and treatment process. Further validation studies and measurements of outcome are needed to verify the impact of these alternative methods of indirect calorimetry.

\section{Summary}

Monitoring exhaled $\mathrm{CO}_{2}$ goes beyond the basic use of evaluating and assessing ventilation. The uses of exhaled $\mathrm{CO}_{2}$ monitoring include improvements in patient safety, utilization in assessing care and evaluating interventions, identifying abnormal physiology, quantifying the severity of illness, and predicting outcomes. In recognition of these significant benefits, the importance of exhaled $\mathrm{CO}_{2}$ monitoring has been increasingly emphasized by practice standards, guidelines, and advisory statements from professional organizations and regulatory agencies.

Future advancements in volumetric capnography will include the capability to continuously estimate Bohr dead space and metabolic rate during mechanical ventilation. These advancements are currently at the verge of technical feasibility, and device manufacturers will soon bring these important enhancements in patient monitoring into clinical practice at the bedside. The critical impact and implications of these valuable monitoring methods utilizing exhaled $\mathrm{CO}_{2}$ will be important for all health-care providers to comprehend and utilize.

\section{REFERENCES}

1. Hederson Y. Applications of gas analysis: IV. The Haldane gas analyzer. J Biol Chem 1918;33(31):31-38.

2. Aitken RS, Clark-Kennedy AE. On the fluctuation in the composition of the alveolar air during the respiratory cycle in muscular exercise. J Physiol 1928;65(4):389-411.

3. Woldring S. Biomedical application of mass spectrometry for monitoring partial pressures: a technical review. J Assoc Adv Med Instrum 1970;4(2):43-56.

4. Riker JB, Haberman B. Expired gas monitoring by mass spectrometry in a respiratory intensive care unit. Crit Care Med 1976;4(5): 223-229.

5. Stock MC. Noninvasive carbon dioxide monitoring. Crit Care Clin 1988;4(3):511-526.

6. Kameyama M, Uehara K, Takatori M, Tada K. Clinical usefulness of EMMA for monitoring end-tidal carbon dioxide. Masui 2013; 62(4):477-480.

7. Kim KW, Choi HR, Bang SR, Lee JW. Comparison of end-tidal $\mathrm{CO}_{2}$ measured by transportable capnometer (EMMA ${ }^{\mathrm{TM}}$ capnograph) and arterial $\mathrm{P}_{\mathrm{CO}_{2}}$ in general anesthesia. J Clin Monit Comput 2015 . doi: 10.1007/s10877-015-9748-x.

8. Whitaker DK. Time for capnography everywhere. Anaesthesia 2011; 66(7):544-549.

9. Siobal MS, Baltz J. A guide to the nutritional assessment and treatment of the critically ill patient. Irving, Texas: American Association for Respiratory Care; 2013:27-36.

10. Hamel DS, Cheifetz IM. Do all mechanically ventilated pediatric patients require continuous capnography? Respir Care Clin N Am 2006;12(3):501-513.

11. Erasmus PD. The use of end-tidal carbon dioxide monitoring to confirm endotracheal tube placement in adult and paediatric intensive care units in Australia and New Zealand. Anaesth Intensive Care 2004;32(5):672-675.

12. Langhan ML, Chen L. Current utilization of continuous end-tidal carbon dioxide monitoring in pediatric emergency departments. Pediatr Emerg Care 2008;24(4):211-213.

13. Manifold CA, Davids N, Villers LC, Wampler DA. Capnography for the nonintubated patient in the emergency setting. J Emerg Med 2013;45(4):626-632.

14. Cheifetz IM, Myers TR. Respiratory therapies in the critical care setting. Should every mechanically ventilated patient be monitored with capnography from intubation to extubation? Respir Care 2007; 52(4):423-438; discussion 438-442.

15. Langhan ML, Kurtz JC, Schaeffer P, Asnes AG, Riera A. Experiences with capnography in acute care settings: a mixed-methods analysis of clinical staff. J Crit Care 2014;29(6):1035-1040.

16. Cumming C, McFadzean J. A survey of the use of capnography for the confirmation of correct placement of tracheal tubes in pediatric intensive care units in the UK. Paediatr Anaesth 2005;15(7):591596.

17. MacLeod BA, Heller MB, Gerard J, Yealy DM, Menegazzi JJ. Verification of endotracheal tube placement with colorimetric endtidal $\mathrm{CO}_{2}$ detection. Ann Emerg Med 1991;20(3):267-270.

18. Varon AJ, Morrina J, Civetta JM. Clinical utility of a colorimetric end-tidal $\mathrm{CO}_{2}$ detector in cardiopulmonary resuscitation and emergency intubation. J Clin Monit 1991;7(4):289-293.

19. Jaffe MB. Mainstream or Sidestream Capnography? Respironics, Inc. 2002. http://www.oem.respironics.com/Downloads/ Main\%20vs\%20Side.pdf. Accessed July 22, 2016.

20. Hess D. Capnometry and capnography: technical aspects, physiologic aspects, and clinical applications. Respir Care 1990;35(6): 557-573.

21. Gravenstein JS, Jaffe MB, Paulus DA. Capnography: clinical aspects: carbon dioxide over time and volume. Cambridge, UK: Cambridge University Press; 2004:321-335.

22. Mehta H, Kashyap R, Trivedi S. Correlation of end-tidal and arterial carbon-dioxide levels in critically ill neonates and children. Indian J Crit Care Med 2014;18(6):348-353.

23. Casati A, Gallioli G, Scandroglio M, Passaretta R, Borghi B, Torri G. Accuracy of end-tidal carbon dioxide monitoring using the NBP-75 microstream capnometer: a study in intubated ventilated and spontaneously breathing nonintubated patients. Eur J Anaesthesiol 2000;17(10):622-626.

24. Barton $\mathrm{CW}$, Wang ES. Correlation of end-tidal $\mathrm{CO}_{2}$ measurements to arterial $\mathrm{P}_{\mathrm{aCO}}$ in nonintubated patients. Ann Emerg Med 1994; 23(3):560-563.

25. Friesen $\mathrm{RH}$, Alswang M. End-tidal $\mathrm{P}_{\mathrm{CO}_{2}}$ monitoring via nasal cannulae in pediatric patients: accuracy and sources of error. J Clin Monit 1996;12(2):155-159.

26. Lightdale JR, Goldmann DA, Feldman HA, Newburg AR, DiNardo JA, Fox VL. Microstream capnography improves patient monitoring during moderate sedation: a randomized, controlled trial. Pediatrics 2006;117(6):e1170-e1178. 


\section{Monitoring Exhaled CARbon Dioxide}

27. Coates BM, Chaize R, Goodman DM, Rozenfeld RA. Performance of capnometry in non-intubated infants in the pediatric intensive care unit. BMC Pediatr 2014;14:163.

28. Standards for Basic Anesthetic Monitoring. American Society of Anesthesiologists. 2015. https://www.asahq.org/ /media/Sites/ ASAHQ/Files/Public/Resources/standards-guidelines/standardsfor-basic-anesthetic-monitoring.pdf. Accessed July 22, 2016.

29. Weinger MB, Brimm JE. End-tidal carbon dioxide as a measure of arterial carbon dioxide during intermittent mandatory ventilation. J Clin Monit 1987;3(2):73-79.

30. Hoffman RA, Krieger BP, Kramer MR, Segel S, Bizousky F, Gazeroglu H, Sackner MA. End-tidal carbon dioxide in critically ill patients during changes in mechanical ventilation. Am Rev Respir Dis 1989;140(5):1265-1268.

31. Razi E, Moosavi GA, Omidi K, Khakpour Saebi A, Razi A. Correlation of end-tidal carbon dioxide with arterial carbon dioxide in mechanically ventilated patients. Arch Trauma Res 2012;1(2):5862.

32. McSwain SD, Hamel DS, Smith PB, Gentile MA, Srinivasan S, Meliones JN, Cheifetz IM. End-tidal and arterial carbon dioxide measurements correlate across all levels of physiologic dead space. Respir Care 2010;55(3):288-293.

33. Yamanaka MK, Sue DY. Comparison of arterial-end-tidal $\mathrm{P}_{\mathrm{CO}_{2}}$ difference and dead space/tidal volume ratio in respiratory failure. Chest 1987;92(5):832-835.

34. Domsky M, Wilson RF, Heins J. Intraoperative end-tidal carbon dioxide values and derived calculations correlated with outcome: prognosis and capnography. Crit Care Med 1995;23(9):1497-1503.

35. Wilson RF, Tyburski JG, Kubinec SM, Warsow KM, Larky HC, Wilson SR, Schermerhorn T. Intraoperative end-tidal carbon dioxide levels and derived calculations correlated with outcome in trauma patients. J Trauma 1996;41(4):606-611.

36. Tyburski JG, Collinge JD, Wilson RF, Carlin AM, Albaran RG, Steffes $\mathrm{CP}$. End-tidal $\mathrm{CO}_{2}$-derived values during emergency trauma surgery correlated with outcome: a prospective study. J Trauma 2002;53(4):738-743.

37. Tyburski JG, Carlin AM, Harvey EH, Steffes C, Wilson RF. Endtidal $\mathrm{CO}_{2}$-arterial $\mathrm{CO}_{2}$ differences: a useful intraoperative mortality marker in trauma surgery. J Trauma 2003;55(5):892-896; discussion 896-897.

38. Rowan CM, Speicher RH, Hedlund T, Ahmed SS, Swigonski NL. Implementation of continuous capnography is associated with a decreased utilization of blood gases. J Clin Med Res 2015;7(2):7175 .

39. Palmon SC, Liu M, Moore LE, Kirsch JR. Capnography facilitates tight control of ventilation during transport. Crit Care Med 1996; 24(4):608-611.

40. Helm M, Schuster R, Hauke J, Lampl L. Tight control of prehospital ventilation by capnography in major trauma victims. Br J Anaesth 2003;90(3):327-332.

41. Davis DP, Dunford JV, Ochs M, Park K, Hoyt DB. The use of quantitative end-tidal capnometry to avoid inadvertent severe hyperventilation in patients with head injury after paramedic rapid sequence intubation. J Trauma 2004;56(4):808-814.

42. Donald MJ, Paterson B. End tidal carbon dioxide monitoring in prehospital and retrieval medicine: a review. Emerg Med J 2006; 23(9):728-730

43. Brazinova A, Majdan M, Leitgeb J, Trimmel H, Mauritz W. Factors that may improve outcomes of early traumatic brain injury care: prospective multicenter study in Austria. Scand J Trauma Resusc Emerg Med 2015;23:53.

44. Thompson JE, Jaffe MB. Capnographic waveforms in the mechanically ventilated patient. Respir Care 2005;50(1):100-108; discussion 108-109.
45. Birmingham PK, Cheney FW, Ward RJ. Esophageal intubation: a review of detection techniques. Anesth Analg 1986;65(8):886-891.

46. Gravenstein JS, Paulus DA, Hayes TJ. Capnography in clinical practice; clinical indications. Stoneham, Massachusetts: Butterworth; 1989:43-49.

47. Bhende MS. End-tidal carbon dioxide monitoring in pediatrics: clinical applications. J Postgrad Med 2001;47(3):215-218.

48. Salthe J, Kristiansen SM, Sollid S, Oglaend B, Søreide E. Capnography rapidly confirmed correct endotracheal tube placement during resuscitation of extremely low birthweight babies $(<1000 \mathrm{~g})$. Acta Anaesthesiol Scand 2006;50(8):1033-1036.

49. Hosono S, Inami I, Fujita H, Minato M, Takahashi S, Mugishima $\mathrm{H}$. A role of end-tidal $\mathrm{CO}_{2}$ monitoring for assessment of tracheal intubations in very low birth weight infants during neonatal resuscitation at birth. J Perinat Med 2009;37(1):79-84.

50. Grmec S. Comparison of three different methods to confirm tracheal tube placement in emergency intubation. Intensive Care Med 2002;28(6):701-704.

51. Grmec S, Mally S. Prehospital determination of tracheal tube placement in severe head injury. Emerg Med J 2004;21(4):518-520.

52. Silvestri S, Ralls GA, Krauss B, Thundiyil J, Rothrock SG, Senn A, et al. The effectiveness of out-of-hospital use of continuous endtidal carbon dioxide monitoring on the rate of unrecognized misplaced intubation within a regional emergency medical services system. Ann Emerg Med 2005;45(5):497-503.

53. Bhende MS, LaCovey DC. End-tidal carbon dioxide monitoring in the prehospital setting. Prehosp Emerg Care 2001;5(2):208-213.

54. Apfelbaum JL, Hagberg CA, Caplan RA, Blitt CD, Connis RT, Nickinovich DG, et al. Practice guidelines for management of the difficult airway: an updated report by the American Society of Anesthesiologists Task Force on Management of the Difficult Airway. Anesthesiology 2013;118(2):251-270.

55. Walsh BK, Crotwell DN, Restrepo RD. Capnography/capnometry during mechanical ventilation: 2011. Respir Care 2011;56(4):503509.

56. Field JM, Hazinski MF, Sayre MR, Chameides L, Schexnayder SM, Hemphill R, et al. Part 1: executive summary: 2010 American Heart Association guidelines for cardiopulmonary resuscitation and emergency cardiovascular care. Circulation 2010;122(18 Suppl 3): S640-S656.

57. Morrison LJ, Neumar RW, Zimmerman JL, Link MS, Newby LK, McMullan PW Jr, et al. Strategies for improving survival after in-hospital cardiac arrest in the United States: 2013 consensus recommendations: a consensus statement from the American Heart Association. Circulation 2013;127(14):1538-1563.

58. Nagler J, Krauss B. Capnography: a valuable tool for airway management. Emerg Med Clin North Am 2008;26(4):881-897, vii.

59. Gravelyn TR, Weg JG. Respiratory rate as an indicator of acute respiratory dysfunction. JAMA 1980;244(10):1123-1125

60. Waugh JB, Epps CA, Khodneva YA. Capnography enhances surveillance of respiratory events during procedural sedation: a metaanalysis. J Clin Anesth 2011;23(3):189-196.

61. The Joint Commission Sentinal Event Alert. Safe use of opioids in hospitals. Issue 49, August 8, 2012. https://www.jointcommission.org/assets/1/18/SEA_49_opioids_8_2_12_final.pdf. Accessed July 22, 2016.

62. Centers for Medicare and Medicaid Services. State operations manual appendix A: survey protocol, regulations and interpretive guidelines for hospitals. Revision 151, November 20, 2015. https://www. cms.gov/Regulations-and-Guidance/Guidance/Manuals/ downloads/som107ap_a_hospitals.pdf. Accessed July 22, 2016.

63. American Society of Anesthesiologists Task Force on Postanesthetic Care. Practice guidelines for postanesthetic care: a report by 


\section{Monitoring Exhaled CARbon Dioxide}

the American Society of Anesthesiologists Task Force on Postanesthetic Care. Anesthesiology 2002;96(3):742-752.

64. Institute for Safe Medication Practice. Fatal PCA adverse events continue to happen... Better patient monitoring is essential to prevent harm. May 30, 2013. https://www.ismp.org/newsletters/ acutecare/showarticle.aspx $?$ id $=50$. Accessed July 22, 2016.

65. Keidan I, Gravenstein D, Berkenstadt H, Ziv A, Shavit I, Sidi A. Supplemental oxygen compromises the use of pulse oximetry for detection of apnea and hypoventilation during sedation in simulated pediatric patients. Pediatrics 2008;122(2):293-298.

66. Fu ES, Downs JB, Schweiger JW, Miguel RV, Smith RA. Supplemental oxygen impairs detection of hypoventilation by pulse oximetry. Chest 2004;126(5):1552-1558.

67. Soto RG, Fu ES, Vila H Jr, Miguel RV. Capnography accurately detects apnea during monitored anesthesia care. Anesth Analg 2004; 99(2):379-382, table of contents.

68. Burton JH, Harrah JD, Germann CA, Dillon DC. Does end-tidal carbon dioxide monitoring detect respiratory events prior to current sedation monitoring practices? Acad Emerg Med 2006;13(5):500504.

69. Kopka A, Wallace E, Reilly G, Binning A. Observational study of perioperative $\mathrm{P}_{\mathrm{tcCO}_{2}}$ and $\mathrm{S}_{\mathrm{pO}_{2}}$ in non-ventilated patients receiving epidural infusion or patient-controlled analgesia using a single earlobe monitor (TOSCA). Br J Anaesth 2007;99(4):567-571.

70. Krauss B, Hess DR. Capnography for procedural sedation and analgesia in the emergency department. Ann Emerg Med 2007;50(2): 172-181.

71. American Society of Anesthesiologists Task Force on Sedation and Analgesia by Non-Anesthesiologists. Practice guidelines for sedation and analgesia by non-anesthesiologists. Anesthesiology 2002; 96(4):1004-1017.

72. Practice guidelines for the prevention, detection, and management of respiratory depression associated with neuraxial opioid administration: an updated report by the American Society of Anesthesiologists Task Force on Neuraxial Opioids and the American Society of Regional Anesthesia and Pain Medicine. Anesthesiology 2016;124(3):535-352.

73. The Joint Commission Sentinal Event Alert. Patient controlled analgesia by proxy. Issue 33, December 20, 2004.

74. Overdyk FJ. PCA Presents Serious Risks. Anesthesia Patient Safety Foundation News Letter 2005;20(2):33.

75. Maddox RR, Williams CK. Clinical experience with capnography monitoring for PCA patients. Anesthesia Patient Safety Foundation News Letter 2012;26(3):47.

76. Wuhrman E, Cooney MF, Dunwoody CJ, Eksterowicz N, Merkel S, Oakes LL. Authorized and unauthorized ("PCA by proxy") dosing of analgesic infusion pumps: position statement with clinical practice recommendations. Pain Manag Nurs 2007;8(1):4-11.

77. Voepel-Lewis T, Marinkovic A, Kostrzewa A, Tait AR, Malviya S. The prevalence of and risk factors for adverse events in children receiving patient-controlled analgesia by proxy or patient-controlled analgesia after surgery. Anesth Analg 2008;107(1):70-75.

78. Jarzyna D, Jungquist CR, Pasero C, Willens JS, Nisbet A, Oakes L, et al. American Society for Pain Management Nursing guidelines on monitoring for opioid-induced sedation and respiratory depression. Pain Manag Nurs 2011;12(3):118-145.e10.

79. Practice advisory on anesthetic care for magnetic resonance imaging: an updated report by the American Society of Anesthesiologists task force on anesthetic care for magnetic resonance imaging. Anesthesiology 2015;122(3):495-520.

80. Cacho G, Pérez-Calle JL, Barbado A, Lledó JL, Ojea R, FernándezRodríguez CM. Capnography is superior to pulse oximetry for the detection of respiratory depression during colonoscopy. Rev Esp Enferm Dig 2010;102(2):86-89.
81. Sivilotti ML, Messenger DW, van Vlymen J, Dungey PE, Murray HE. A comparative evaluation of capnometry versus pulse oximetry during procedural sedation and analgesia on room air. CJEM 2010; 12(5):397-404.

82. Deitch K, Miner J, Chudnofsky CR, Dominici P, Latta D. Does end tidal $\mathrm{CO}_{2}$ monitoring during emergency department procedural decrease the incidence of hypoxic events? A randomized, controlled trial. Ann Emerg Med 2010;55(3):258-264.

83. Langhan ML, Shabanova V, Li FY, Bernstein SL, Shapiro ED. A randomized controlled trial of capnography during sedation in a pediatric emergency setting. Am J Emerg Med 2015;33(1):25-30.

84. Hatlestad D. Capnography in sedation and pain management. Emerg Med Serv 2005;34(3):65-69.

85. Miner JR, Heegaard W, Plummer D. End-tidal carbon dioxide monitoring during procedural sedation. Acad Emerg Med 2002;9(4): 275-280.

86. Pantazopoulos C, Xanthos T, Pantazopoulos I, Papalois A, Kouskouni E, Iacovidou N. A review of carbon dioxide monitoring during adult cardiopulmonary resuscitation. Heart Lung Circ 2015; 24(11):1053-1061.

87. Kodali BS, Urman RD. Capnography during cardiopulmonary resuscitation: current evidence and future directions. J Emerg Trauma Shock 2014;7(4):332-340.

88. Sheak KR, Wiebe DJ, Leary M, Babaeizadeh S, Yuen TC, Zive D, et al. Quantitative relationship between end-tidal carbon dioxide and CPR quality during both in-hospital and out-of-hospital cardiac arrest. Resuscitation 2015;89:149-154.

89. Pokorná M, Necas E, Kratochvíl J, Skripský R, Andrlík M, Franek $\mathrm{O}$. A sudden increase in partial pressure end-tidal carbon dioxide $\left(\mathrm{P}_{\mathrm{ETCO}_{2}}\right)$ at the moment of return of spontaneous circulation. J Emerg Med 2010;38(5):614-621.

90. Sehra R, Underwood $\mathrm{K}$, Checchia P. End tidal $\mathrm{CO}_{2}$ is a quantitative measure of cardiac arrest. Pacing Clin Electrophysiol 2003;26(1 Pt 2):515-517.

91. Touma O, Davies M. The prognostic value of end tidal carbon dioxide during cardiac arrest: a systematic review. Resuscitation 2013;84(11):1470-1479.

92. Kalenda Z. The capnogram as a guide to the efficacy of cardiac massage. Resuscitation 1978;6(4):259-263.

93. Weil MH, Bisera J, Trevino RP, Rackow EC. Cardiac output and end-tidal carbon dioxide. Crit Care Med 1985;13(11):907-909.

94. Falk JL, Rackow EC, Weil MH. End-tidal carbon dioxide concentration during cardiopulmonary resuscitation. N Engl J Med 1988; 318(10):607-611.

95. Ornato JP, Garnett AR, Glauser FL. Relationship between cardiac output and the end-tidal carbon dioxide tension. Ann Emerg Med 1990;19(10):1104-1106.

96. Callaham M, Barton C. Prediction of outcome of cardiopulmonary resuscitation from end-tidal carbon dioxide concentration. Crit Care Med 1990;18(4):358-362.

97. Wayne MA, Levine RL, Miller CC. Use of end-tidal carbon dioxide to predict outcome in prehospital cardiac arrest. Ann Emerg Med 1995;25(6):762-767.

98. Levine RL, Wayne MA, Miller CC. End-tidal carbon dioxide and outcome of out-of-hospital cardiac arrest. N Engl J Med 1997; 337(5):301-306.

99. Grmec S, Klemen P. Does the end-tidal carbon dioxide $\left(\mathrm{EtCO}_{2}\right)$ concentration have prognostic value during out-of-hospital cardiac arrest? Eur J Emerg Med 2001;8(4):263-269.

100. Kolar M, Krizmaric M, Klemen P, Grmec S. Partial pressure of end-tidal carbon dioxide successful predicts cardiopulmonary resuscitation in the field: a prospective observational study. Crit Care 2008;12(5):R115. 


\section{Monitoring Exhaled CARbon Dioxide}

101. Hatlestad D. Capnography as a predictor of the return of spontaneous circulation. Emerg Med Serv 2004;33(8):75-80.

102. Jaffe MB. Using the features of the time and volumetric capnogram for classification and prediction. J Clin Monit Comput 2016. doi: 10.1007/s10877-016-9830-z.

103. Fowler WS. Lung function studies; the respiratory dead space. Am J Physiol 1948;154(3):405-416.

104. Rickaby DA, Hanus MJ, Hamilton LH. A computer program for calculating respiratory anatomic dead space. Int J Biomed Comput 1981;12(2):125-138.

105. Suter PM, Fairley B, Isenberg MD. Optimum end-expiratory airway pressure in patients with acute pulmonary failure. N Engl J Med 1975;292(6):284-289.

106. Fletcher R, Jonson B, Cumming G, Brew J. The concept of deadspace with special reference to the single breath test for carbon dioxide. Br J Anaesth 1981;53(1):77-88

107. Fletcher R. Deadspace, invasive and non-invasive. Br J Anaesth 1985;57(3):245-249

108. Beydon L, Uttman L, Rawal R, Jonson B. Effects of positive endexpiratory pressure on dead space and its partitions in acute lung injury. Intensive Care Med 2002;28(9):1239-1245.

109. Nik Hisamuddin NA, Rashidi A, Chew KS, Kamaruddin J, Idzwan $\mathrm{Z}$, Teo AH. Correlations between capnographic waveforms and peak flow meter measurement in emergency department management of asthma. Int J Emerg Med 2009;2(2):83-89.

110. Howe TA, Jaalam K, Ahmad R, Sheng CK, Nik Ab Rahman NH. The use of end-tidal capnography to monitor non-intubated patients presenting with acute exacerbation of asthma in the emergency department. J Emerg Med 2011;41(6):581-589.

111. Carter EP. A note upon the technique and accuracy of the method of Douglas and Haldane for calculating the dead space in breathing. J Exp Med 1914;20(1):81-91.

112. Hedley-Whyte J, Pontoppidan H, Morris MJ. The response of patients with respiratory failure and cardiopulmonary disease to different levels of constant volume ventilation. J Clin Invest 1966; 45(10):1543-1554.

113. MacKinnon JC, Houston PL, McGuire GP. Validation of the Deltatrac metabolic cart for measurement of dead-space-to-tidalvolume ratio. Respir Care 1997;42(8):761-764.

114. Lum L, Saville A, Venkataraman ST. Accuracy of physiologic deadspace measurement in intubated pediatric patients using a metabolic monitor: comparison with the Douglas bag technique. Crit Care Med 1998;26(4):760-764.

115. Kallet RH, Daniel BM, Garcia O, Matthay MA. Accuracy of physiologic deadspace measurements in patients with acute respiratory distress syndrome using volumetric capnography: comparison with the metabolic monitor method. Respir Care 2005;50(4):462-467.

116. Siobal MS, Ong H, Valdes J, Tang J. Calculation of physiologic dead space: comparison of ventilator volumetric capnography to measurements by metabolic analyzer and volumetric $\mathrm{CO}_{2}$ monitor. Respir Care 2013;58(7):1143-1151.

117. Bohr C. Uber die Lungeatmung. Skand Arch Physiol 1891;2:236238. Article in German.

118. Enghoff H. Volumen inefficax: bemerkungen zur frage des schadlichen raumes. Upsala Lak̈arefor̈en For̈h 1938;44:191-218. Article in German.

119. Nunes S, Valta P, Takala J. Changes in respiratory mechanics and gas exchange during the acute respiratory distress syndrome. Acta Anaesthesiol Scand 2006;50(1):80-91.

120. Lamy M, Fallat RJ, Koeniger E, Dietrich HP, Ratliff JL, Eberhart $\mathrm{RC}$, et al. Pathologic features and mechanisms of hypoxemia in adult respiratory distress syndrome. Am Rev Respir Dis 1976; 114(2):267-284.
121. Gattinoni L, Bombino M, Pelosi P, Lissoni A, Pesenti A, Fumagalli $\mathrm{R}$, Tagliabue M. Lung structure and function in different stages of severe adult respiratory distress syndrome. JAMA 1994;271(22): 1772-1779.

122. Ralph DD, Robertson HT, Weaver LJ, Hlastala MP, Carrico CJ, Hudson LD. Distribution of ventilation and perfusion during positive end expiratory pressure in the adult respiratory distress syndrome. Am Rev Respir Dis 1985;131(1):54-60.

123. Robertson HT. Dead space: the physiology of wasted ventilation. Eur Respir J 2015;45(6):1704-1716.

124. Bein T, Reber A, Stjernström H, Metz C, Taeger K, Hedenstierna G. Ventilation-perfusion ratio in patients with acute respiratory insufficiency. Anaesthesist 1996;45(4):337-342.

125. Shimada Y, Yoshiya I, Tanaka K, Sone S, Sakurai M. Evaluation of the progress and prognosis of adult respiratory distress syndrome: simple respiratory physiologic measurement. Chest 1979;76(2):180186.

126. Raurich JM, Vilar M, Colomar A, Ibáñez J, Ayestarán I, PérezBárcena J, Llompart-Pou JA. Prognostic value of the pulmonarydead-space fraction during the early and intermediate phases of acute respiratory distress syndrome. Respir Care 2010;55(3):282287.

127. Nuckton TJ, Alonso JA, Kallet RH, Daniel BM, Pittet JF, Eisner MD, Matthay MA. Pulmonary dead-space fraction as a risk factor for death in the acute respiratory distress syndrome. N Engl J Med 2002;346(17):1281-1286

128. Kallet RH, Alonso JA, Pittet JF, Matthay MA. Prognostic value of the pulmonary dead-space fraction during the first 6 days of acute respiratory distress syndrome. Respir Care 2004;49(9):1008-1014.

129. Cepkova M, Kapur V, Ren X, Quinn T, Zhuo H, Foster E, et al. Pulmonary dead space fraction and pulmonary artery systolic pressure as early predictors of clinical outcome in acute lung injury. Chest 2007;132(3):836-842.

130. Lucangelo U, Bernabè F, Vatua S, Degrassi G, Villagrà A, Fernandez R, et al. Prognostic value of different deadspace indices in mechanically ventilated patients with acute lung injury and ARDS. Chest 2008;133(1):62-71.

131. Kallet RH, Zhuo H, Liu KD, Calfee CS, Matthay MA. The association between physiologic dead-space fraction and mortality in subjects with ARDS enrolled in a prospective multi-center clinical trial. Respir Care 2014;59(11):1611-1618.

132. Maisch S, Reissmann H, Fuellekrug B, Weismann D, Rutkowski T, Tusman G, Bohm SH. Compliance and deadspace fraction indicate an optimal level of positive end-expiratory pressure after recruitment in anesthetized patients. Anesth Analg 2008;106(1):175-181, table of contents.

133. Tusman G, Suarez-Sipmann F, Böhm SH, Pech T, Reissmann H, Meschino $\mathrm{G}$, et al. Monitoring deadspace during recruitment and PEEP titration in an experimental model. Intensive Care Med 2006; 32(11):1863-1871.

134. Gattinoni L, Vagginelli F, Carlesso E, Taccone P, Conte V, Chiumello $\mathrm{D}$, et al. Decrease in $\mathrm{P}_{\mathrm{aCO}}$ with prone position is predictive of improved outcome in acute respiratory distress syndrome. Crit Care Med 2003;31(12):2727-2733.

135. El-Baradey GF, El-Shamaa NS. Compliance versus dead space for optimum positive end expiratory pressure determination in acute respiratory distress syndrome. Indian J Crit Care Med 2014;18(8): 508-512.

136. Hubble CL, Gentile MA, Tripp DS, Craig DM, Meliones JN, Cheifetz IM. Deadspace to tidal volume ratio predicts successful extubation in infants and children. Crit Care Med 2000;28(6):20342040.

137. González-Castro A, Suárez-Lopez V, Gómez-Marcos V, GonzálezFernandez C, Iglesias-Posadilla D, Burón-Mediavilla J, et al. Utility 


\section{Monitoring Exhaled CARbon Dioxide}

of the deadspace fraction $\left(\mathrm{V}_{\mathrm{D}} / \mathrm{V}_{\mathrm{T}}\right)$ as a predictor of extubation success. Med Intensiva 2011;35(9):529-538.

138. Riou Y, Chaari W, Leteurtre S, Leclerc F. Predictive value of the physiological deadspace/tidal volume ratio in the weaning process of mechanical ventilation in children. J Pediatr (Rio J) 2012;88(3): 217-221. doi: 10.2223/JPED.2190.

139. Burki NK. The dead space to tidal volume ratio in the diagnosis of pulmonary embolism. Am Rev Respir Dis 1986;133(4):679-685.

140. Kline JA, Arunachlam M. Preliminary study of the capnogram waveform area to screen for pulmonary embolism. Ann Emerg Med 1998;32(3 Pt 1):289-296.

141. Hemnes AR, Newman AL, Rosenbaum B, Barrett TW, Zhou C, Rice TW, Newman JH. Bedside end-tidal $\mathrm{CO}_{2}$ tension as a screening tool to exclude pulmonary embolism. Eur Respir J 2010;35(4): 735-741.

142. Sanchez O, Wermert D, Faisy C, Revel MP, Diehl JL, Sors H, Meyer G. Clinical probability and alveolar dead space measurement for suspected pulmonary embolism in patients with an abnormal D-dimer test result. J Thromb Haemost 2006;4(7):1517-1522.

143. Kline JA, Meek S, Boudrow D, Warner D, Colucciello S. Use of the alveolar dead space fraction $(\mathrm{Vd} / \mathrm{Vt})$ and plasma D-dimers to exclude acute pulmonary embolism in ambulatory patients. Acad Emerg Med 1997;4(9):856-863.

144. Kline JA, Israel EG, Michelson EA, O’Neil BJ, Plewa MC, Portelli DC. Diagnostic accuracy of a bedside D-dimer assay and alveolar dead-space measurement for rapid exclusion of pulmonary embolism: a multicenter study. JAMA 2001;285(6):761-768.

145. Rodger MA, Jones G, Rasuli P, Raymond F, Djunaedi H, Bredeson CN, Wells PS. Steady-state end-tidal alveolar dead space fraction and D-dimer: bedside tests to exclude pulmonary embolism. Chest 2001;120(1):115-159.

146. Kurt OK, Alpar S, Sipit T, Guven SF, Erturk H, Demirel MK, et al. The diagnostic role of capnography in pulmonary embolism. Am J Emerg Med 2010;28(4):460-465.

147. Yoon YH, Lee SW, Jung DM, Moon SW, Horn JK, Hong YS. The additional use of end-tidal alveolar dead space fraction following Ddimer test to improve diagnostic accuracy for pulmonary embolism in the emergency department. Emerg Med J 2010;27(9):663-667.

148. Kline JA, Kubin AK, Patel MM, Easton EJ, Seupal RA. Alveolar dead space as a predictor of severity of pulmonary embolism. Acad Emerg Med 2000;7(6):611-617.
149. Tusman G, Sipmann FS, Bohm SH. Rationale of deadspace measurement by volumetric capnography. Anesth Analg 2012;114(4): 866-874.

150. Riley RL, Cournand A. Ideal alveolar air and the analysis of ventilation-perfusion relationships in the lungs. J Appl Physiol 1949; 1(12)825-847.

151. Riley RL, Cournand A. Analysis of factors affecting partial pressures of oxygen and carbon dioxide in gas and blood of the lungs: theory. J Appl Physiol 1951;4(2):77-101.

152. Tusman G, Scandurra A, Böhm SH, Suarez-Sipmann F, Clara F. Model fitting of volumetric capnograms improves calculations of airway dead space and slope of phase III. J Clin Monit Comput 2009;23(4):197-206.

153. Tusman G, Sipmann FS, Borges JB, Hedenstierna G, Böhm SH. Validation of Bohr deadspace measured by volumetric capnography. Intensive Care Med 2011;37(5):870-874.

154. Tang Y, Turner MJ, Baker AB. Effects of alveolar dead-space, shunt and $\dot{\mathrm{V}} / \mathrm{Q}$ distribution on respiratory dead-space measurements. Br J Anaesth 2005;95(4):538-548.

155. Suarez-Sipmann F, Santos A, Böhm SH, Borges JB, Hedenstierna G, Tusman G. Corrections of Enghoff's dead space formula for shunt effects still overestimate Bohr's dead space. Respir Physiol Neurobiol 2013;189(1):99-105.

156. Medgraphics website. CCM Express operators manual. http://mgc diagnostics.com/images/uploads/CCMexpress_sellsheet_060065rF_ web.pdf. Accessed July 22, 2016.

157. Siobal MS, Hammoudeh H, Snow M. Accuracy of resting energy expenditure calculated by a modification of the abbreviated Weir equation in mechanically ventilated adult ICU patients (Abstract). Respir Care 2012;57(10):1721.

158. Hess D, Daugherty A, Large E, Agarwal NN. A comparison of four methods of determining caloric requirements of mechanically ventilated trauma patients. Respir Care 1986;31(12):11971203.

159. McCamish MA, Dean RE, Ouellette TR. Assessing energy requirements of patients on respirators. JPEN J Parenter Enteral Nutr 1981;5(6):513-516.

160. Wilmore DW. The metabolic management of the critically ill. New York: Plenum Medical Book Company; 1977:9. 